\title{
Small Molecules from Nature Targeting G-Protein Coupled Cannabinoid Receptors: Potential Leads for Drug Discovery and Development
}

\author{
Charu Sharma, ${ }^{1}$ Bassem Sadek, ${ }^{2}$ Sameer N. Goyal, ${ }^{3}$ Satyesh Sinha, \\ Mohammad Amjad Kamal, ${ }^{5,6}$ and Shreesh Ojha ${ }^{2}$ \\ ${ }^{1}$ Department of Internal Medicine, College of Medicine and Health Sciences, United Arab Emirates University, \\ P.O. Box 17666, Al Ain, Abu Dhabi, UAE \\ ${ }^{2}$ Department of Pharmacology and Therapeutics, College of Medicine and Health Sciences, United Arab Emirates University, \\ P.O. Box 17666, Al Ain, Abu Dhabi, UAE \\ ${ }^{3}$ Department of Pharmacology, R. C. Patel Institute of Pharmaceutical Education \& Research, Shirpur, Mahrastra 425405, India \\ ${ }^{4}$ Department of Internal Medicine, College of Medicine, Charles R. Drew University of Medicine and Science, Los Angeles, \\ CA 90059, USA \\ ${ }^{5}$ King Fahd Medical Research Center, King Abdulaziz University, Jeddah, Saudi Arabia \\ ${ }^{6}$ Enzymoics, 7 Peterlee Place, Hebersham, NSW 2770, Australia
}

Correspondence should be addressed to Shreesh Ojha; shreeshojha@uaeu.ac.ae

Received 24 April 2015; Accepted 24 August 2015

Academic Editor: Ki-Wan Oh

Copyright (C) 2015 Charu Sharma et al. This is an open access article distributed under the Creative Commons Attribution License, which permits unrestricted use, distribution, and reproduction in any medium, provided the original work is properly cited.

\begin{abstract}
The cannabinoid molecules are derived from Cannabis sativa plant which acts on the cannabinoid receptors types 1 and $2\left(\mathrm{CB}_{1}\right.$ and $\mathrm{CB}_{2}$ ) which have been explored as potential therapeutic targets for drug discovery and development. Currently, there are numerous cannabinoid based synthetic drugs used in clinical practice like the popular ones such as nabilone, dronabinol, and $\Delta^{9}$ tetrahydrocannabinol mediates its action through $\mathrm{CB}_{1} / \mathrm{CB}_{2}$ receptors. However, these synthetic based Cannabis derived compounds are known to exert adverse psychiatric effect and have also been exploited for drug abuse. This encourages us to find out an alternative and safe drug with the least psychiatric adverse effects. In recent years, many phytocannabinoids have been isolated from plants other than Cannabis. Several studies have shown that these phytocannabinoids show affinity, potency, selectivity, and efficacy towards cannabinoid receptors and inhibit endocannabinoid metabolizing enzymes, thus reducing hyperactivity of endocannabinoid systems. Also, these naturally derived molecules possess the least adverse effects opposed to the synthetically derived cannabinoids. Therefore, the plant based cannabinoid molecules proved to be promising and emerging therapeutic alternative. The present review provides an overview of therapeutic potential of ligands and plants modulating cannabinoid receptors that may be of interest to pharmaceutical industry in search of new and safer drug discovery and development for future therapeutics.
\end{abstract}

\section{Introduction}

The endocannabinoid system (ECS), an important lipid signaling and immunomodulator system, has begun to reap attention as it is widely involved in modulating host of physiological responses ranging from appetite, respiration, metabolism, inflammation, pain, neurotransmission, and so forth. The ECS is comprised of the G-protein coupled receptors
(GPCRs) such as cannabinoid receptors 1 and $2\left(\mathrm{CB}_{1}\right.$ and $\left.\mathrm{CB}_{2}\right)$; cannabinoid receptor ligands also known as endocannabinoids are characterized by arachidonyl ethanolamide (anandamide, AEA) and 2-arachidonoyl glycerol (2-AG) $[1,2]$ and the enzymes involved in synthesis and degradation of the endocannabinoids. The levels of the endocannabinoids in the tissues are maintained by the critical balance between their biosynthesis (involving phospholipase D and diacylglycerol 
lipase-dependent and other pathways) and cellular uptake as well as degradation by the enzymes: fatty acid amide hydrolase (FAAH) and/or monoacylglycerol lipases (MAGL) [3]. Recently, some additional GPCRs such as GPR18, GPR55, and GPR119 have been recognized as members of the cannabinoid family; however the physiological significance is yet to be established [4].

The $\mathrm{CB}_{1}$ and $\mathrm{CB}_{2}$ receptors are well characterized members of the GPCR which couple to G-proteins in the $G_{i / o}$ family. The activation of the $\mathrm{CB}_{1}$ and $\mathrm{CB}_{2}$ receptors causes the numerous intracellular effects which may be cell type and ligand specific and involve the inhibition of various voltage gated $\mathrm{Ca}^{+2}$ channels and adenylate cyclase activity and the activation of $\mathrm{K}^{+}$channels, resulting in lower levels of cAMP along with activation of MAPK pathways [5]. The $\mathrm{CB}_{1}$ receptors regulate the activities of adenylyl cyclase, ERK, glycogen synthase kinase 3 , and calcium and potassium channels [5]. The $\mathrm{CB}_{2}$ receptor couples to $\mathrm{G}_{\mathrm{i}}$ to mediate their cellular effects via inhibition of adenylyl cyclase and regulation of transcription factors [5]. The inhibition of activation of cannabinoid receptors and inhibition of endocannabinoid degradative enzymes have been found to enhance endocannabinoid signaling and harness the therapeutic potential of the ECS as an important therapeutic target $[6,7]$.

In recent years, research is focusing on the unique neuromodulator system, ECS, which is named after the plant that led to its discovery [3]. The pervasive and varied regulatory actions of the ECS in maintenance of general health and diseases have supported the regulatory approval of several molecules of natural and synthetic origin as novel drugs that modulate the cannabinoid receptor signaling mediated by $\mathrm{CB}_{1}$ or $\mathrm{CB}_{2}$ receptors or alter the ECS activity by reducing the endocannabinoid tone by inhibiting FAAH and MAGL $[6,8]$. The potential role for ECS-based therapies must be explored with a clear and complete picture of the potential beneficial and adverse effects that will occur from exogenous activation and/or inhibition of ECS using cannabinoid based medicines. The modulation of ECS by cannabinoid based medicines holds remarkable therapeutic promise in a variety of pathological conditions including neuropathic pain, diabetic complications, obesity, stroke, hypertension, cancer, psychosis, glaucoma, epilepsy, addiction, and neurodegenerative diseases including Alzheimer's disease, multiple sclerosis, and Parkinson's disease [7, 9].

The cannabinoids comprise compounds that produced endogenous (endocannabinoids), synthetic, and active components of Cannabis sativa, a traditional source of about 100 natural cannabinoids also known as phytocannabinoids [10]. The physiological effects of these phytocannabinoids derived from Cannabis sativa have been known since ancient times and used for both leisure and medicinal purposes and have generated immense interest for pharmaceutical development. Phytocannabinoids are defined as agents of plant origin that interacts with either of cannabinoid receptors or shares chemical similarity with cannabinoids or both. It is known that they arise from the interaction of $\Delta^{9}$-tetrahydrocannabinol $\left(\Delta^{9}\right.$-THC), the main psychoactive constituent of the plant; Cannabis sativa interact with cannabinoid receptors [11-13].
Several classes of synthetic cannabinoid agents have been developed for the therapeutic targeting of the several components of ECS. Among them, rimonabant (SR141716A; Acomplia), a $\mathrm{CB}_{1}$ receptor antagonist/inverse agonist, makes a therapeutic success for the management of obesity but was withdrawn because of safety concerns about its psychiatric adverse effects, particularly increased incidence of depression, anxiety, and suicidal tendencies [10]. Numerous illicitly produced synthetic cannabinoid agonists typically acting as agonists at $\mathrm{CB}_{1}$ receptors that mimic the effects of $\Delta^{9}$-THC have been reported to drug monitoring agencies. Synthetic agents produce atypical pharmacological effects such as hypertension, seizures, and panic attacks. This is explained by atypical effect of $\mathrm{CB}_{1}$ receptor agonist, which is apparently higher for synthetic cannabinoids: JWH-018 and JWH-073 compared with $\Delta^{9}$-THC, the agent mainly accountable for the behavioral effects of cannabis [14].

In parallel to the development of synthetic analogues modulating ECS components, the pharmaceutical companies followed several approaches to target the cannabinoid receptors and modulate ECS activity including the development of phytocannabinoid compounds isolated from the plants. Currently, several drugs which modulate the $\mathrm{CB}_{1}$ or $\mathrm{CB}_{2}$ receptors are at present in the clinic such as Cesamet (nabilone), Marinol (dronabinol; $\Delta^{9}$-THC), and Sativex (cannabidiol and $\Delta^{9}$-THC). The agents, nabilone and dronabinol, are indicated to relieve chemotherapy-induced nausea and vomiting. Dronabinol is also used as appetizer, while the plant derived cannabis preparation. Sativex is frequently indicated for the symptomatic relief of neuropathic pain in adults with multiple sclerosis and spasticity and is also used as an adjunct to relieve pain in adult patients with advanced cancer.

The potential agents derived from plants targeting ECS have become a central focus of contemporary translational research for diverse indications with important unmet medical demands. The present review focuses on medicinal plants that have shown to modulate the ECS appearing as therapeutic possibility for diseases which involves ECS dysregulation. The present review focuses on natural small molecules, isolated and characterized as cannabinoid receptors modulator. These naturally derived molecules could offer the potential leads for future drug discovery and the targeting of endocannabinoid dysregulation or the diseases where endocannabinoid modulation represents an important therapeutic target. Additionally, the medicinal plants modulating ECS are also provided that can be subjected for the isolation of components possessing cannabinoid receptor agonist or antagonist activity. The actions of cannabinoid compounds partly involve several non-CB receptor dependent mechanisms and are regarded as an additive beneficial effect of phytocannabinoids molecules for multitargeting.

\section{Phytochemicals as Lead Compounds Targeting ECS}

Following the progress in chemical isolation and screening techniques, several novel lead molecules were isolated and characterized from the natural products for the development of new drugs. In current years, numerous molecules have 


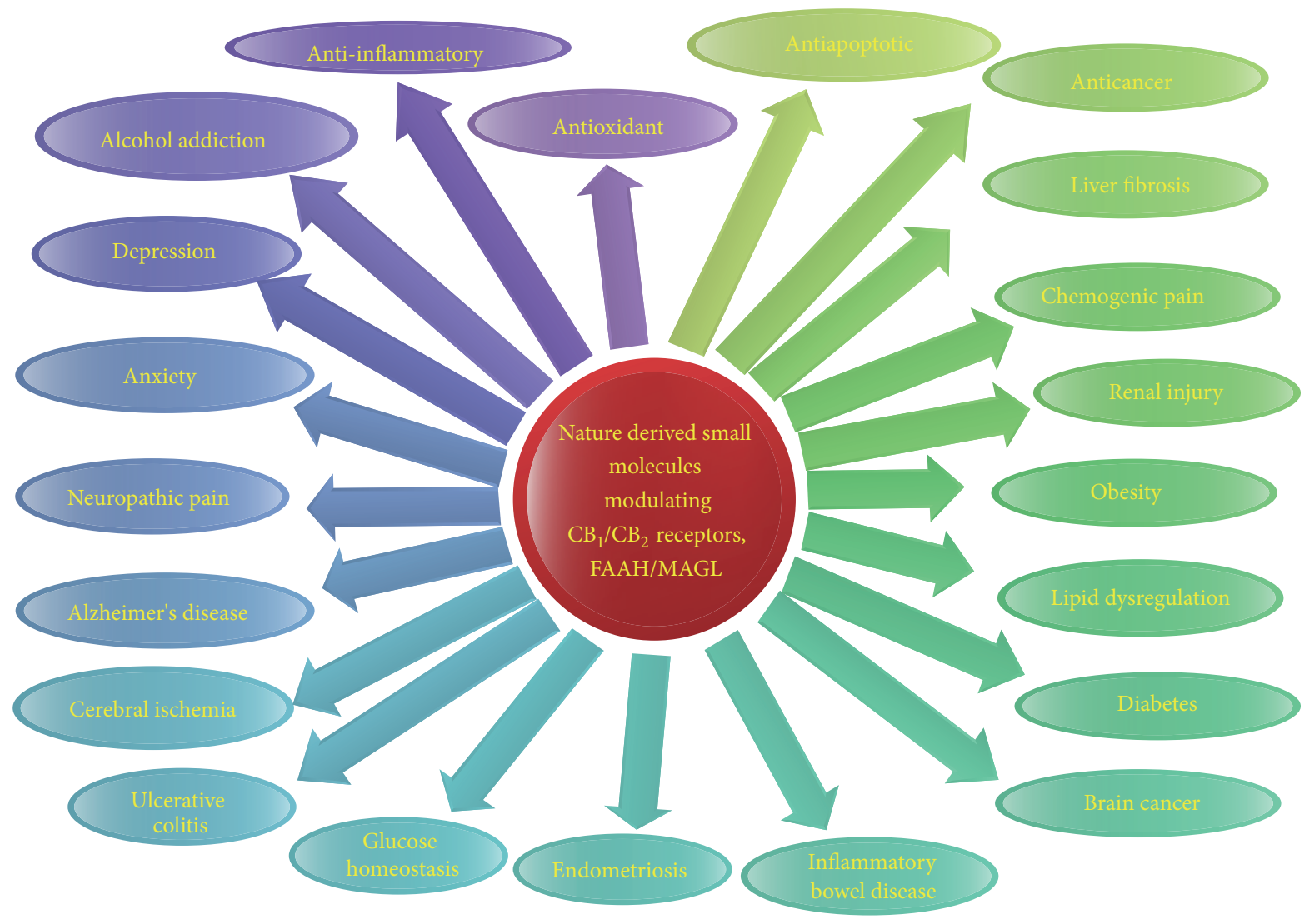

FIGURE 1: Cannabinoid receptor mediated medicinal and pharmacological activities of lead compounds isolated from medicinal plants.

been isolated and characterized which showed cannabinoid receptor affinity, efficacy, and therapeutic benefits in the in vitro, in silico, and in vivo studies [15-21]. The agents were also found to inhibit endocannabinoid metabolizing enzymes, FAAH, DAGL, and MAGL inhibitors, and exhibit their potential efficacy mediated by the cannabinoid mediated mechanism [7]. Figure 1 depicts the cannabinoid receptors and endocannabinoid metabolizing enzymes mediated pharmacological effects and therapeutic benefits of small molecules derived from nature.

Directly acting ligands are the compounds which exhibit high binding affinities (in low nanomolar to micromolar range) to the cannabinoid receptors and exert distinct functional effects behaving either as agonists, inverse agonists, partial agonists, or antagonist [22], whereas indirectly acting ligands target either the key proteins in the ECS which regulate endocannabinoid levels in tissues or the allosteric sites on the $\mathrm{CB}_{1}$ receptors [6]. Recently, availability of different tools such as radioligand and $\left[{ }^{35} \mathrm{~S}\right] \mathrm{GTP} \gamma \mathrm{S}$ binding assays facilitated the characterization of agonists, antagonists, and inverse agonists for cannabinoid receptors. Some practical guidelines and specific considerations in order to characterize the ligands using these assays are available for cannabinoid receptors. The agonists which bind to $\mathrm{CB}_{1}$ and $\mathrm{CB}_{2}$ receptors show little selectivity; however the $\mathrm{CB}_{1}$ and $\mathrm{CB}_{2}$ receptor antagonists are highly selective usually in nanomolar affinity at the respective receptor. This allows differentiating the $\mathrm{CB}_{1}$ or $\mathrm{CB}_{2}$ mediated mechanism and responses of in vitro and in vivo studies. In addition to the selective $\mathrm{CB}_{1}$ and $\mathrm{CB}_{2}$ antagonists that are used to block agonist effects, there are also genetic tools $\left(\mathrm{CB}_{1} / \mathrm{CB}_{2}\right.$ receptor knockout mice) available to the research community. There are several nonselective agonists which are available which prefer either $\mathrm{CB}_{1}$ or $\mathrm{CB}_{2}$ receptors $[4,10]$.

In this review, the small molecules derived from natural products targeting ECS components are described in order to provide them as standard sources of templates for developing novel ligands for pharmaceutical development and clinical usage. The database searches using Medline/PubMed, EMBASE, Google Scholar, and Science Direct were conducted to include all the available published literature in the present review paper. The years of coverage for literature retrieval were from 1975 to May 25, 2015. The search was limited to English language publications; however if the abstract was available in English, then it is included in the present paper. For literature search, the standard $\mathrm{MeSH}$ such as natural products, cannabinoid receptor modulators, cannabinoid agents, medicinal plants, and cannabinoid ligands and articles all together on cannabinoid ligands were used in the database search engines. In almost all cases, the original articles were obtained and the relevant data was extracted. 
Table 1 depicts the physicochemical properties and drug likeness of phytochemicals and Figure 2 represents the chemical structure of phytochemicals modulating cannabinoid receptors and endocannabinoid metabolizing enzymes. Table 2 shows the therapeutic properties and underlying cannabinoid mediated mechanism of small natural molecules modulating cannabinoid receptors and endocannabinoid metabolizing enzymes. The cannabinoids are chemically defined as terpenoalcoholic compounds and chemical class of molecules identified till date is provided in Table 3. Recently, some selective full agonists and antagonists for specific $\mathrm{CB}_{1}$ and $\mathrm{CB}_{2}$ receptors have been recognized. Among the phytocannabinoids, $\beta$-caryophyllene is one which has been identified as a full agonist for $\mathrm{CB}_{2}$ receptors and isolated from cannabis as well as noncannabis plant [18]. This generated interest in characterizing the cannabinoid-like compounds or $\mathrm{CB}$ receptor modulating ligands from plants other than cannabis, which is considered a traditional source of phytocannabinoids.

\subsection{Alkylamides Derivatives}

2.1.1. Alkylamides from Echinacea angustifolia. Various studies have demonstrated that the $\mathrm{CB}_{2}$ receptors are primarily found in immune cells and participate in immune regulation $[16,17,23,24]$. Thus, interactions of alkylamides with $\mathrm{CB}_{2}$ receptors can be demonstrated by immunomodulatory effect of Echinacea preparations [21, 25, 26]. Two alkylamides, dodeca-2E,4E,8Z,10Z-tetraenoic acid isobutylamide and dodeca-2E,4E-dienoic acid isobutylamide, have been isolated from Echinacea purpurea and Echinacea angustifolia [21, 27]. Chemically, alkylamides show structural similarity with anandamide and bind with $\mathrm{CB}_{2}$ receptors more potently than endogenous cannabinoids with the $K_{i}$ values $\left(\mathrm{CB}_{2}\right.$ approximately $60 \mathrm{nM} ; \mathrm{CB}_{1}>1500 \mathrm{nM}$ ) and act as full agonist on $\mathrm{CB}_{2}$ receptors in nanomolar range. Also, the molecular modeling studies have shown that alkylamide compounds bind in the solvent-accessible cavity in $\mathrm{CB}_{2}$ receptors which is directed by the $\mathrm{H}$-bonding and pi-pi interactions [27]. Furthermore, these compounds raised total intracellular $\mathrm{Ca}^{2+}$ in $\mathrm{CB}_{2}$-positive promyelocytic HL 60 cells as demonstrated by abrogation of the effects by SR144528 and also inhibit the enzyme, FAAH [27]. Though, the ketolactones found in Echinacea pallida (purple cornflower) did not show cannabinoid activity [28]. Another alkylamide, undeca-2-ene-8,10diynoic acid isolated from Echinacea spp., stimulates 3T3-L1 differentiation mediated by PPAR- $\gamma$ activity demonstrating that anti-inflammatory property of alkylamides is due to polyvalent activity $[29,30]$.

2.1.2. Alkylamides from Otanthus maritimus L. Several alkylamides have been isolated from dichloromethane root extract of Otanthus maritimus L. (family: Asteraceae), an aromatic herb growing on sandy beaches along the Mediterranean coasts. These compounds exhibit cannabinoid receptors binding affinity as demonstrated in the in vitro, in silico, and in vivo studies $[15,31]$. The in silico studies were carried out by generating $3 \mathrm{D}$ models of $\mathrm{hCB}_{2}$ receptors in homology modeling [31]. The root extract showed high binding affinity to $\mathrm{CB}_{1}$ and $\mathrm{CB}_{2}$ receptors with $K_{i}$ values of $2.2 \mu \mathrm{g} / \mathrm{mL}$ and $1.3 \mu \mathrm{g} / \mathrm{mL}$, respectively, and moderate affinity to $\mu$ - and $\delta$ opioid receptors in radioligand assay. Among the several identified compounds from extract, a tertiary alkylamide, 1-[(2E,4E,8Z)-tetradecatrienoyl] piperidine, showed most potent binding affinity with both $\mathrm{CB}_{1}$ and $\mathrm{CB}_{2}$ receptors with a $K_{i}$ value of $0.8 \mu \mathrm{M}$ and $0.16 \mu \mathrm{M}$, respectively. It showed $\mathrm{CB}_{2}$ selectivity with a $K_{i} \mathrm{CB}_{1} / K_{i} \mathrm{CB}_{2}=5$, with significant potency $\left(K_{i}=160 \mathrm{nM}\right)$ [31]. Other isolated alkylamides as dodeca-2E,4E-dienoic acid isobutylamide, tetradeca- $2 E, 4 E$ dienoic acid isobutylamide, tetradeca- $2 E, 4 E, 8 Z$-trienoic acid isobutylamide, and 1-[(2E,4E,8Z)-tetradecatrienoyl] piperidine showed highest affinity for $\mathrm{CB}_{2}$ receptors and show less affinity to opioid receptors. In regard to $\mathrm{CB}_{2}$ receptor affinity, the structure activity relationship (SAR) studies reveal the influence of double bonds geometry in dodecatetraenoic acid isobutylamides. The alkylamides, N-substituted with an isobutyl or dimethylbutyl group and represented by a secondary alkylamide as the amide part, appear to be involved in the $\mathrm{CB}_{2}$ receptor interaction [32]. However, it is observed that the tertiary amide $1-[(2 E, 4 E, 8 Z)$-tetradecatrienoyl $]$ piperidine which contains a piperidinyl moiety linked to a C14 acyl chain appears to have more affinity and potency on $\mathrm{CB}_{2}$ than dodeca-2E,4E-dienoic acid isobutylamide, an active principle of Echinacea species [15]. Overall, alkylamides from Echinacea and Otanthus spp. appear to be a good source of $\mathrm{CB}_{2}$ receptors ligands in drug discovery.

2.2. $\alpha, \beta$-Amyrin. The pentacyclic triterpene and mixture $(1: 1)$ of two isomers, $\alpha, \beta$-amyrin, are mainly constituent of the resin of Protium kleinii and Protium heptaphyllum. The $\mathrm{CB}$ receptor mediated anti-inflammatory and antinociceptive effect of $\alpha, \beta$-amyrin has been shown in mice model of neuropathic pain [33]. It reduced mechanical and thermal hyperalgesia and inflammation induced by complete Freund's adjuvant and by partial sciatic nerve ligation in animal models. The antinociceptive responses were mediated by activation of the ECS and comparable to the synthetic molecules, ACEA and JWH-133. The reversals of antinociceptive effects by $\mathrm{CB}_{1}$ or $\mathrm{CB}_{2}$ receptor antagonists (AM251 and AM630, resp.) as well as knockdown of the $\mathrm{CB}_{1} / \mathrm{CB}_{2}$ gene demonstrate $\mathrm{CB}$ activity. It binds to $\mathrm{CB}_{1}$ receptors with a high affinity $\left(K_{i}=\right.$ $0.133 \mathrm{nM})$ and to $\mathrm{CB}_{2}$ receptors with a lower affinity $\left(K_{i}=\right.$ $1989 \mathrm{nM}$ ) along with absence of behavioral disturbances. The binding to $\mathrm{CB}_{1}$ receptors was 200-300-fold more potent than $\Delta^{9}$-THC. However, in contrast to $\Delta^{9}$-THC and 2-AG, $\alpha, \beta-$ amyrin showed an unusual 15000-fold more binding selectivity for $\mathrm{CB}_{1}$ receptors over $\mathrm{CB}_{2}$. Furthermore, $\alpha, \beta$-amyrin decreased proinflammatory cytokines and chemokines and prevented activation of the transcriptional factors: NF- $\kappa \mathrm{B}$ and cyclic adenosine monophosphate response element binding (CREB) and the expression of cyclooxygenase-2 (COX-2) in footpads and spinal cords of mice. It also prevented upregulation of $\mathrm{CB}_{2} \mathrm{R}$ mRNA but failed to affect $\mathrm{CB}_{1}$ receptor mRNA upregulation as well as cortical levels of both $\mathrm{CB}_{1}$ and $\mathrm{CB}_{2}$ receptors. In another study, Chicca et al. [34] showed $\mathrm{CB}$ receptor binding interactions of $\alpha, \beta$-amyrin using $\mathrm{hCB}_{1} / \mathrm{hCB}_{2}$ receptors transfected $\mathrm{CHO}-\mathrm{K} 1$ cells and its effects on the endocannabinoid transport in U937 cells. 


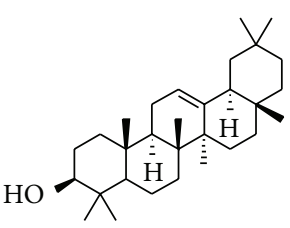

Amyrin<smiles>C/C=C/C=C/C=C/c1c(O)cc(CC=C(C)C)c(O)c1C=O</smiles>

Auroglaucin<smiles>COc1ccc(-c2coc3cc(O)cc(O)c3c2=O)cc1</smiles>

Biochanin A

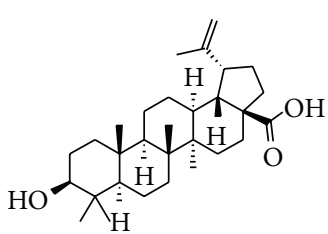

Betulinic acid<smiles></smiles>

Celastrol<smiles>C=C1CCC=C(C)CC[C@@H]2C(C)C[C@H]12</smiles>

Beta-caryophyllene<smiles></smiles>

Chelerythrine<smiles>OC[C@H]1O[C@@H](OC2=C(c3ccc(O)c(O)c3)[O+]c3cc(O)cc(O)c3C2)[C@H](O)[C@@H](O)[C@H]1O</smiles>

Cyanidin-3-O-glucoside<smiles>COc1cc(/C=C/C(=O)CC(=O)/C=C/c2ccc(O)c(OC)c2)ccc1O</smiles>

Curcumin<smiles>Oc1cc(O)c2cc(O)c(-c3ccc(O)c(O)c3)[o+]c2c1</smiles>

Cyanidin

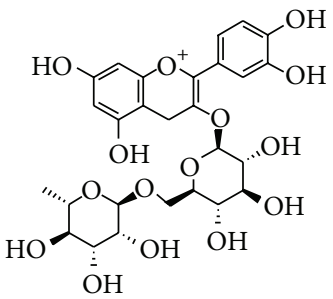

Cyanidin-3-O-rutinoside

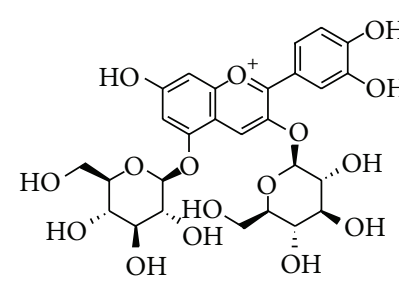

Cyanidin-3,5-di-O-glucoside<smiles>Oc1cc(O)c2cc(O)c(-c3cc(O)c(O)c(O)c3)[o+]c2c1</smiles>

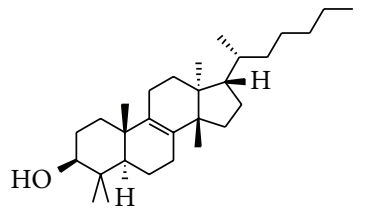

Euphol<smiles>OCC1O[C@@H]([O+]c2cc(O)cc(O)c2O)C(c2ccc(O)c(O)c2)[O+]c2cc(O)cc(O)c21</smiles>

Cyanidin-3-galactoside<smiles>C=CCc1ccc(O)c(-c2cc(CC=C)ccc2O)c1</smiles>

Grenadamide

Guineensine

Leucettamol A

Magnolol<smiles>C=CCc1ccc(O)c(-c2ccc(OC)c(CC=C)c2)c1</smiles>

Methylhonokio

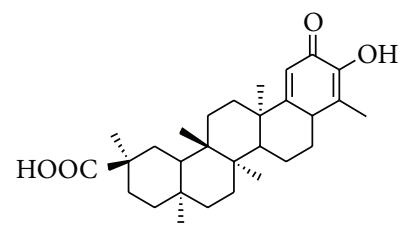

Pristimerin<smiles>O=c1c(O)c(-c2ccc(O)c(O)c2)oc2cc(O)cc(O)c12</smiles>

Quercetin

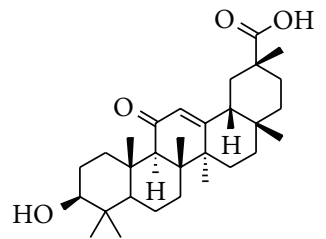

$18 \beta$-Glycyrrhetinic acid 


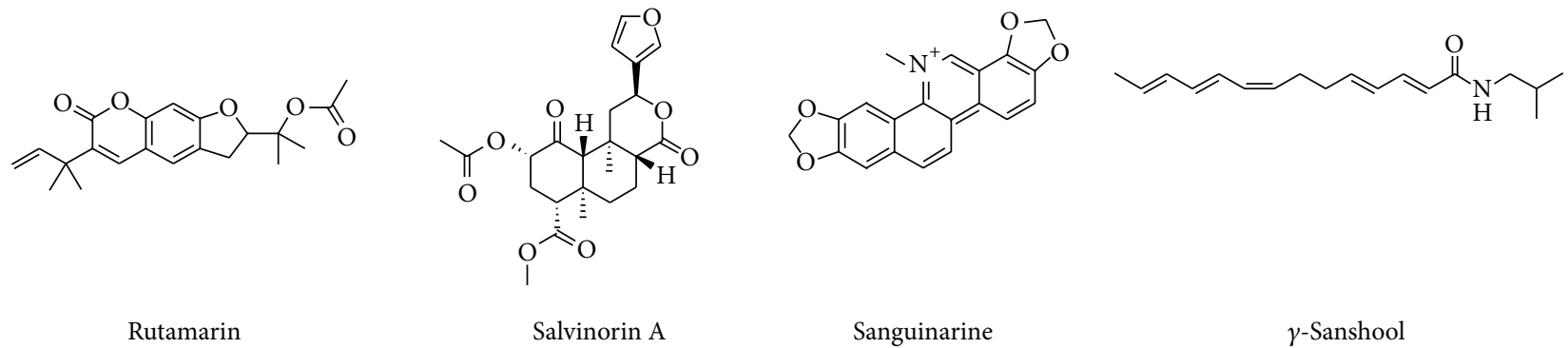<smiles>Cc1c(O)c2c(c(C)c1O[C@@H]1OC(CO[C@@H]3OCC(CO)(CO)[C@H]3O)[C@@H](O)[C@H](O)C1O)O[C@@H](c1ccc(O)cc1)CC2=O</smiles>

Miconioside B<smiles>O=C(/C=C/C=C/c1ccc2c(c1)OCO2)N1CCCCC1</smiles>

Piperidine<smiles>COc1cc(-c2[o+]c3cc(O)cc(O)c3cc2O)cc(OC)c1O</smiles>

Malvidin<smiles>COc1ccc(C2CC(=O)c3c(O)c(C)c(O)c(C)c3O2)cc1</smiles>

Matteucinol<smiles>C[C@H]1C/C=C\CC/C=C/C(=O)Cc2cccc(O)c2C(=O)O1</smiles>

Monocillin II<smiles>CCCCCCCCC(=O)NCc1ccc(O)c(OC)c1</smiles>

Nonivamide<smiles>COc1cc(-c2[o+]c3cc(O)cc(O)c3cc2O)ccc1O</smiles>

Peonidin<smiles>Oc1ccc(-c2[o+]c3cc(O)cc(O)c3cc2O)cc1</smiles>

Pelargonidin<smiles>CO[C@@H](C)C[C@H](O)[C@H](/C=C\C=C/C(=O)Cc1c(Cl)c(O)cc(O)c1Cl)OC</smiles>

Radicicol

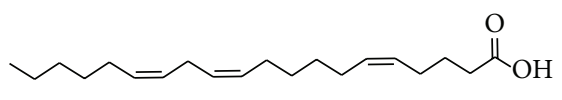

Sciadonic acid

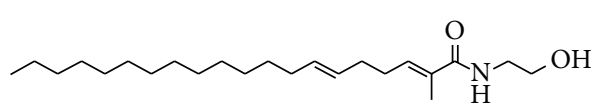

Semiplenamides A

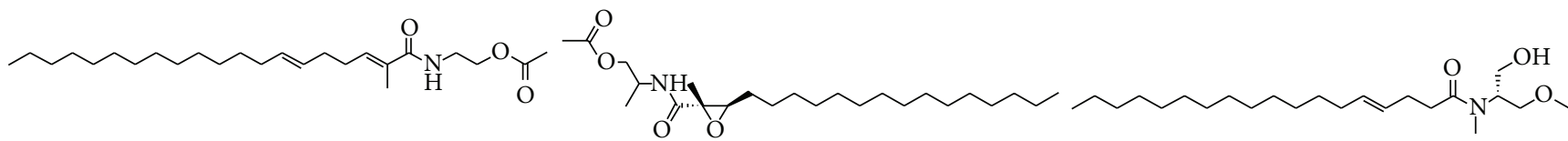

Semiplenamides B

Semiplenamides $\mathrm{G}$

Serinolamide A<smiles>CCCCCCCCCCCCC/C=C/CCC(=O)N(C)[C@@H](CO)COC</smiles>

(E)-N-[(2R)-1-Hydroxy-3-methoxypropan-2-yl]-Nmethyloctadec-4-enamide

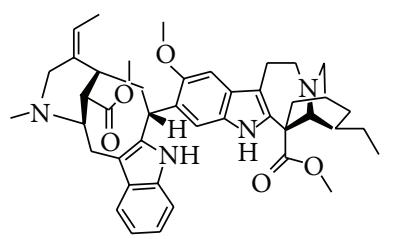

Voacamine<smiles>COc1ccc(/C=C/c2cc(OC)cc(=O)o2)cc1</smiles>

Yangonin

FIGURE 2: Chemical structure of isolated phytochemicals targeting endocannabinoid system. 
TABLE 1: The physicochemical properties and common and IUPAC name of lead compounds modulating cannabinoid receptors.

\begin{tabular}{|c|c|c|}
\hline Molecule \& IUPAC name & Chemical properties & Common name(s) \\
\hline $\begin{array}{l}\text { Amyrin } \\
(3 \mathrm{~S}, 4 \mathrm{aR}, 6 \mathrm{aR}, 6 \mathrm{bS}, 8 \mathrm{aR}, 12 \mathrm{aR}, 14 \mathrm{aR}, 14 \mathrm{bR})-4,4,6 \mathrm{a}, 6 \mathrm{~b}, 8 \mathrm{a}, 11,11,14 \mathrm{~b}- \\
\text { Octamethyl-1,2,3,4a,5,6,7,8,9,10,12,12a,14,14a- } \\
\text { tetradecahydropicen-3-ol }\end{array}$ & $\begin{array}{l}\text { M. Wt.: } 426.71[\mathrm{~g} / \mathrm{mol}] \\
\text { M. formula: } \mathrm{C}_{30} \mathrm{H}_{50} \mathrm{O} \\
\text { XLogP3-AA: } 9.2 \\
\text { H-bond donor/acceptor: } 1 / 1\end{array}$ & Olean-12-en-3-beta-ol \\
\hline $\begin{array}{l}\text { Auroglaucin } \\
\text { 2-[(1E,3E,5E)-Hepta-1,3,5-trienyl]-3,6-dihydroxy-5-(3- } \\
\text { methylbut-2-enyl)benzaldehyde }\end{array}$ & $\begin{array}{l}\text { M. Wt.: } 298.37618[\mathrm{~g} / \mathrm{mol}] \\
\text { M. formula: } \mathrm{C}_{19} \mathrm{H}_{22} \mathrm{O}_{3} \\
\text { XLogP3-AA: } 5.4 \\
\text { H-bond donor/acceptor: } 2 / 3\end{array}$ & Auroglaucine \\
\hline $\begin{array}{l}\text { Biochanin A } \\
\text { 5,7-Dihydroxy-3-(4-methoxyphenyl)chromen-4-one }\end{array}$ & $\begin{array}{l}\text { M. Wt.: } 284.26[\mathrm{~g} / \mathrm{mol}] \\
\text { M. formula: } \mathrm{C}_{16} \mathrm{H}_{12} \mathrm{O}_{5} \\
\text { XLogP3-AA: } 3 \\
\text { H-bond donor/acceptor: } 2 / 5\end{array}$ & $\begin{array}{l}\text { 5,7-Dihydroxy- } 4^{\prime}- \\
\text { methoxyisoflavone }\end{array}$ \\
\hline
\end{tabular}

Betulinic acid

(1R,3aS,5aR,5bR,7aR,9S,11aR,11bR,13aR,13bR)-9-Hydroxy- $\quad$ M. Wt.: 456.70 [g/mol]

5a,5b,8,8,11a-pentamethyl-1-prop-1-en-2-yl-

M. formula: $\mathrm{C}_{30} \mathrm{H}_{48} \mathrm{O}_{3}$ XLogP3-AA: 8.2

1,2,3,4,5,6,7,7a,9,10,11,11b,12,13,13a,13b-hexa-

decahydrocyclopenta[a]chrysene-3a-carboxylic

H-bond donor/acceptor: 2/3

3 $\beta$-Hydroxy-20(29)-lupaene-28oic acid acid

\section{Celastrol}

(2R,4aS,6aR,6aS,14aS,14bR)-10-Hydroxy-2,4a,6a,6a,9,14ahexamethyl-11-oxo-1,3,4,5,6,13,14,14b-octahydropicene-2carboxylic acid
M. Wt.: 450.60962 [g/mol]

M. formula: $\mathrm{C} 29 \mathrm{H} 38 \mathrm{O} 4$ XLogP3: 5.9

H-bond donor/acceptor: 2/4
Celastrol; tripterine; tripterin; celastrol, Celastrus scandens

Beta-caryophyllene

(1R,4E,9S)-4,11,11-Trimethyl-8-

methylidenebicyclo[7.2.0] undec-4-ene

M. Wt.: 204.35 [g/mol]

M. formula: $\mathrm{C}_{15} \mathrm{H}_{24}$

XLogP3-AA: 4.4

(-)-trans-Caryophyllene

H-bond donor/acceptor: 0/0

Chelerythrine

1,2-Dimethoxy-12-methyl-[1,3] benzodioxolo[5,6-

c]phenanthridin-12-ium

M. Wt.: $348.37[\mathrm{~g} / \mathrm{mol}]$

M. formula: $\mathrm{C}_{21} \mathrm{H}_{18} \mathrm{NO}_{4}{ }^{+}$

XLogP3-AA: 4.6

H-bond donor/acceptor: 0/4

M. Wt.: 368.37 [g/mol]

M. formula: $\mathrm{C}_{21} \mathrm{H}_{20} \mathrm{O}_{6}$

$\begin{array}{lc}\text { (1E,6E)-1,7-Bis(4-hydroxy-3-methoxyphenyl)hepta-1,6-diene- } & \text { XLogP3-AA: 3.2 } \\ \text { 3,5-dione } & \text { H-bond donor/acceptor: } 2 / 6\end{array}$

$\begin{array}{lc}\text { (1E,6E)-1,7-Bis(4-hydroxy-3-methoxyphenyl)hepta-1,6-diene- } & \text { XLogP3-AA: } 3.2 \\ \text { 3,5-dione } & \text { H-bond donor/acceptor: 2/6 }\end{array}$

Cyanidin

2-(3,4-Dihydroxyphenyl)chromenylium-3,5,7-triol

M. Wt.: 287.24 [g/mol]

M. formula: $\mathrm{C}_{15} \mathrm{H}_{11} \mathrm{O}_{6}^{+}$

H-bond donor/acceptor: 5/5

methyl(1,3)benzodioxolo(5,6-

c)phenanthridinium

Cyanidin-3,5-di-O-glucoside

(2S,3R,4S,5S,6R)-2-[2-(3,4-Dihydroxyphenyl)-7-hydroxy-3-

[(2S,3R,4S,5S,6R)-3,4,5-trihydroxy-6-(hydroxymethyl)oxan-2-

M. Wt.: $611.52[\mathrm{~g} / \mathrm{mol}]$

M. formula: $\mathrm{C}_{27} \mathrm{H}_{31} \mathrm{O}_{16}{ }^{+}$

H-bond donor/acceptor: 11/15

Cyanin,

Cyanidol, $3,5,7,3^{\prime}, 4^{\prime}-$

pentahydroxyflavylium

yl]oxychromenylium-5-yl] oxy-6-(hydroxymethyl)oxane-3,4,5triol

Cyanidin-3-O-glucoside

2-(3,4-Dihydroxyphenyl)-5-hydroxy-3-[(3R,4S,5S,6R)-3,4,5-

trihydroxy-6-(hydroxymethyl)oxan-2-yl] oxychromen-7-one

Cyanidin 3-galactoside

(2S,5R)-2-[2-(3,4-Dihydroxyphenyl)-5,7-dihydroxychro-

menylium-3-yl] oxy-6-(hydroxymethyl)oxane-3,4,5-triol

M. Wt.: 448.37 [g/mol]
M. formula: $\mathrm{C}_{21} \mathrm{H}_{20} \mathrm{O}_{11}$
XLogP3-AA: -1.2

H-bond donor/acceptor: 7/11

M. Wt.: 449.38 [g/mol]

M. formula: $\mathrm{C}_{21} \mathrm{H}_{21} \mathrm{O}_{11}{ }^{+}$ H-bond donor/acceptor: $8 / 10$

Cyanidin 3-O-rutinoside

2-[[6-[2-(3,4-Dihydroxyphenyl)-5,7-dihydroxy-

chromenylium-3-yl]oxy-3,4,5-trihydroxyoxan-2-yl]methoxy]-

6-methyloxane-3,4,5-triol

M. Wt.: 630.97 [g/mol]

M. formula: $\mathrm{C}_{27} \mathrm{H}_{31} \mathrm{ClO}_{15}$

H-bond donor/acceptor: 10/15
Idaein, cyanidin 3-O-galactoside

Meralop, 3-O-rutino

sylcyanidin, $7,4^{\prime}$ -

dihydroxyflavilium

chloride 
TABle 1: Continued.

\begin{tabular}{|c|c|c|}
\hline Molecule \& IUPAC name & Chemical properties & Common name(s) \\
\hline $\begin{array}{l}\text { Delphinidin } \\
\text { 2-(3,4,5-Trihydroxyphenyl)chromenylium-3,5,7-triol }\end{array}$ & $\begin{array}{c}\text { M. Wt.: } 303.24[\mathrm{~g} / \mathrm{mol}] \\
\text { M. formula: } \mathrm{C}_{15} \mathrm{H}_{11} \mathrm{O}_{7}^{+} \\
\text {H-bond donor/acceptor: } 6 / 6\end{array}$ & $\begin{array}{l}3,3^{\prime}, 4^{\prime}, 5,5^{\prime}, 7- \\
\text { Hexahydroxyflavylium }\end{array}$ \\
\hline $\begin{array}{l}\text { Euphol } \\
\text { (3S,5R,10S,13S,14S,17S)-4,4,10,13,14-Pentamethyl-17-[(2R)-6- } \\
\text { methylhept-5-en-2-yl]-2,3,5,6,7,11,12,15,16,17-decahydro-1H- } \\
\text { cyclopenta[a]phenanthren-3-ol }\end{array}$ & $\begin{array}{l}\text { M. Wt.: } 426.71[\mathrm{~g} / \mathrm{mol}] \\
\text { M. formula: } \mathrm{C}_{30} \mathrm{H}_{50} \mathrm{O} \\
\text { XLogP3-AA: } 8.9 \\
\text { H-bond donor/acceptor: } 1 / 1\end{array}$ & Eupha-8,24-dienol \\
\hline $\begin{array}{l}\text { 18ß-Glycyrrhetinic acid } \\
(2 \mathrm{~S}, 4 \mathrm{aS}, 6 \mathrm{aR}, 6 \mathrm{aS}, 6 \mathrm{bR}, 10 \mathrm{~S}, 12 \mathrm{aS}, 14 \mathrm{bR})-10-H y d r o x y- \\
\text { 2,4a,6a,6b,9,9,12a-heptamethyl-13-oxo-3,4,5,6,6a,7,8,8a, } \\
\text { 10,11,12,14b-dodecahydro-1H-picene-2-carboxylic acid }\end{array}$ & $\begin{array}{l}\text { M. Wt.: } 470.68[\mathrm{~g} / \mathrm{mol}] \\
\text { M. formula: } \mathrm{C}_{30} \mathrm{H}_{46} \mathrm{O}_{4} \\
\text { XLogP3-AA: } 6.4 \\
\text { H-bond donor/acceptor: } 2 / 4\end{array}$ & $\begin{array}{l}18 \beta \text {-Glycyrrhetic acid, } \\
\text { glycyrrhetinic acid }\end{array}$ \\
\hline $\begin{array}{l}\text { Grenadamide } \\
\text { (5E)-N-[(E)-10-Chloro-4,6-dimethyl-5-oxodec-9-en-2-yl]-5- } \\
\text { (chloromethylidene)octanamide }\end{array}$ & $\begin{array}{l}\text { M. Wt.: } 404.4141[\mathrm{~g} / \mathrm{mol}] \\
\text { M. formula: } \mathrm{C}_{21} \mathrm{H}_{35} \mathrm{Cl}_{2} \mathrm{NO}_{2} \\
\text { XLogP3-AA: } 6.1 \\
\text { H-bond donor/acceptor: } 1 / 2 \\
\end{array}$ & - \\
\hline $\begin{array}{l}\text { Guineensine } \\
\text { (2E,4E,12E)-13-(1,3-Benzodioxol-5-yl)-N-(2- } \\
\text { methylpropyl)trideca-2,4,12-trienamide }\end{array}$ & $\begin{array}{l}\text { M. Wt.: } 383.52[\mathrm{~g} / \mathrm{mol}] \\
\text { M. formula: } \mathrm{C}_{24} \mathrm{H}_{33} \mathrm{NO}_{3} \\
\text { XLogP3-AA: } 6.8 \\
\text { H-bond donor/acceptor: } 1 / 3\end{array}$ & Pipyahyine \\
\hline $\begin{array}{l}\text { Leucettamol A } \\
\text { (2S,3R,5Z,8Z,11Z,14Z,17Z,20Z,28R,29S)-2,29- } \\
\text { Diaminotriaconta-5,8,11,14,17,20-hexaene-3,28-diol }\end{array}$ & $\begin{array}{l}\text { M. Wt.: } 472.74[\mathrm{~g} / \mathrm{mol}] \\
\text { M. formula: } \mathrm{C}_{30} \mathrm{H}_{52} \mathrm{~N}_{2} \mathrm{O}_{2} \\
\text { XLogP3-AA: } 6.2 \\
\text { H-bond donor/acceptor: } 4 / 4\end{array}$ & - \\
\hline $\begin{array}{l}\text { Magnolol } \\
\text { 2-(2-Hydroxy-5-prop-2-enylphenyl)-4-prop-2-enylphenol }\end{array}$ & $\begin{array}{l}\text { M. Wt.: } 266.33[\mathrm{~g} / \mathrm{mol}] \\
\text { M. formula: } \mathrm{C}_{18} \mathrm{H}_{18} \mathrm{O}_{2} \\
\text { XLogP3-AA: } 5 \\
\text { H-bond donor/acceptor: } 2 / 2\end{array}$ & $\begin{array}{l}5,5^{\prime} \text {-Diallyl-2,2' - } \\
\text { dihydroxybiphenyl }\end{array}$ \\
\hline $\begin{array}{l}\text { Methylhonokiol } \\
\text { 2-(4-Methoxy-3-prop-2-enylphenyl)-4-prop-2-enylphenol }\end{array}$ & $\begin{array}{l}\text { M. Wt.: } 280.36[\mathrm{~g} / \mathrm{mol}] \\
\text { M. formula: } \mathrm{C}_{19} \mathrm{H}_{20} \mathrm{O}_{2} \\
\text { XLogP3-AA: } 5.3 \\
\text { H-bond donor/acceptor: } 1 / 2\end{array}$ & $\begin{array}{l}4^{\prime} \text {-Methoxy- } 3^{\prime}, 5 \text {-di-2-propenyl- } \\
\text { (1,1' - biphenyl)-2-ol,4- } \\
\text { methoxyhonokiol }\end{array}$ \\
\hline $\begin{array}{l}\text { Pristimerin } \\
\text { Methyl (2R,4aS,6aR,6aS,14aS,14bR)-10-hydroxy- } \\
\text { 2,4a,6a,6a,9,14a-hexamethyl-11-oxo-1,3,4,5,6,13,14,14b- } \\
\text { octahydropicene-2-carboxylate }\end{array}$ & $\begin{array}{l}\text { M. Wt.: } 464.63[\mathrm{~g} / \mathrm{mol}] \\
\text { M. formula: } \mathrm{C}_{30} \mathrm{H}_{40} \mathrm{O}_{4} \\
\text { XLogP3-AA: } 6.3 \\
\text { H-bond donor/acceptor: } 1 / 4\end{array}$ & $\begin{array}{l}\text { 24-Nor-D:A-friedooleana- } \\
\text { 1(10),3,5,7-tetraen-29-oic } \\
\text { acid }\end{array}$ \\
\hline $\begin{array}{l}\text { Quercetin } \\
\text { 2-(3,4-Dihydroxyphenyl)-3,5,7-trihydroxychromen-4-one }\end{array}$ & $\begin{array}{l}\text { M. Wt.: } 302.23[\mathrm{~g} / \mathrm{mol}] \\
\text { M. formula: } \mathrm{C}_{15} \mathrm{H}_{10} \mathrm{O}_{7} \\
\text { XLogP3: } 1.5 \\
\text { H-bond donor/acceptor: } 5 / 7\end{array}$ & - \\
\hline $\begin{array}{l}\text { Resveratrol } \\
\text { 5-[(E)-2-(4-Hydroxyphenyl)ethenyl]benzene-1,3-diol }\end{array}$ & $\begin{array}{l}\text { M. Wt.: } 228.24[\mathrm{~g} / \mathrm{mol}] \\
\text { M. formula: } \mathrm{C}_{14} \mathrm{H}_{12} \mathrm{O}_{3} \\
\text { XLogP3-AA: } 3.1 \\
\text { H-bond donor/acceptor: } 3 / 3\end{array}$ & $3,4^{\prime}, 5$-Trihydroxystilbene \\
\hline $\begin{array}{l}\text { Rutamarin } \\
\text { 2-[6-(2-Methylbut-3-en-2-yl)-7-oxo-2,3-dihydrofuro[3,2- } \\
\text { g]chromen-2-yl]propan-2-yl } \\
\text { acetate }\end{array}$ & $\begin{array}{l}\text { M. Wt.: } 356.41[\mathrm{~g} / \mathrm{mol}] \\
\text { M. formula: } \mathrm{C}_{21} \mathrm{H}_{24} \mathrm{O}_{5} \\
\text { XLogP3-AA: } 4.4 \\
\text { H-bond donor/acceptor: } 0 / 5\end{array}$ & - \\
\hline $\begin{array}{l}\text { Salvinorin A } \\
\text { Methyl (2S,4aR,6aR,7R,9S,10aS,10bR)-9-acetyloxy-2-(furan-3- } \\
\text { yl)-6a,10b-dimethyl-4,10-dioxo-2,4a,5,6,7,8,9,10a-octahydro- } \\
\text { 1H-benzo[f]isochromene-7-carboxylate }\end{array}$ & $\begin{array}{l}\text { M. Wt.: } 432.46[\mathrm{~g} / \mathrm{mol}] \\
\text { M. formula: } \mathrm{C}_{23} \mathrm{H}_{28} \mathrm{O}_{8} \\
\text { XLogP3-AA: } 2.5 \\
\text { H-bond donor/acceptor: } 0 / 8\end{array}$ & Divinorin A \\
\hline Sanguinarine & $\begin{array}{c}\text { M. Wt.: } 332.32[\mathrm{~g} / \mathrm{mol}] \\
\text { M. formula: } \mathrm{C}_{20} \mathrm{H}_{14} \mathrm{NO}_{4}^{+} \\
\text {XLogP3-AA: } 4.4 \\
\text { H-bond donor/acceptor: } 0 / 4\end{array}$ & $\begin{array}{l}\text { Dimethylene } \\
\text { dioxybenzphenanthridine }\end{array}$ \\
\hline
\end{tabular}


TABLE 1: Continued.

\begin{tabular}{|c|c|c|}
\hline Molecule \& IUPAC name & Chemical properties & Common name(s) \\
\hline $\begin{array}{l}\gamma \text {-Sanshool } \\
(2 \mathrm{E}, 4 \mathrm{E}, 8 \mathrm{Z}, 10 \mathrm{E}, 12 \mathrm{E})-\mathrm{N}-\text { Propan-2-yltetradeca-2,4,8,10,12- } \\
\text { pentaenamide }\end{array}$ & $\begin{array}{l}\text { M. Wt.: } 259.38[\mathrm{~g} / \mathrm{mol}] \\
\text { M. formula: } \mathrm{C}_{17} \mathrm{H}_{25} \mathrm{NO} \\
\quad \text { XLogP3-AA: } 4.3 \\
\text { H-bond donor/acceptor: } 1 / 1\end{array}$ & - \\
\hline $\begin{array}{l}\text { Miconioside B } \\
\text { (2S)-7-[(2S,4S,5S)-6-[[(2R,3S)-3,4-Dihydroxy-4- } \\
\text { (hydroxylmethyl)oxolan-2-yl] oxymethyl]-3,4,5-tri- } \\
\text { hydroxyoxan-2-yl] oxy-5-hydroxy-2-(4-hydroxy-phenyl)-6,8- } \\
\text { dimethyl-2,3-dihydrochromen-4-one }\end{array}$ & $\begin{array}{l}\text { M. Wt.: } 594.56[\mathrm{~g} / \mathrm{mol}] \\
\text { M. formula: } \mathrm{C}_{28} \mathrm{H}_{34} \mathrm{O}_{14} \\
\quad \text { XLogP3-AA: }-0.5 \\
\text { H-bond donor/acceptor: } 8 / 14\end{array}$ & $\begin{array}{l}\text { Farrerol } \\
\text { 7-O-beta-D-apiofuranosyl }(1->6)- \\
\text { beta-D-glucopyranoside }\end{array}$ \\
\hline
\end{tabular}

\section{Piperine}

(2E,4E)-5-(1,3-Benzodioxol-5-yl)-1-piperidin-1-ylpenta-2,4dien-1-one

\section{Wt.: 285.33 [g/mol]}

M. formula: $\mathrm{C}_{17} \mathrm{H}_{19} \mathrm{NO}_{3}$ $\mathrm{X} \log \mathrm{P} 3: 3.5$

H-bond donor/acceptor: 0/3

M. Wt.: 331.29 [g/mol]

M. formula: $\mathrm{C}_{17} \mathrm{H}_{15} \mathrm{O}_{7}^{+}$

H-bond donor/acceptor: $4 / 6$

Malvidin

2-(4-Hydroxy-3,5-dimethoxyphenyl)chromenylium-3,5,7-triol

Matteucinol

5,7-Dihydroxy-2-(4-methoxyphenyl)-6,8-dimethyl-2,3-

dihydrochromen-4-one

Monocillin II

(4E,8E,11S)-15-Hydroxy-11-methyl-12-

oxabicyclo[12.4.0] octadeca-1(14),4,8,15,17-pentaene-3,13-dione

Nonivamide

$\mathrm{N}$-[(4-Hydroxy-3-methoxyphenyl)methyl]nonanamide

Peonidin

2-(4-Hydroxy-3-methoxyphenyl)chromenylium-3,5,7-triol

Pelargonidin

2-(4-Hydroxyphenyl)chromenylium-3,5,7-triol

Radicicol

Sciadonic acid

(5E,11E,14E)-Icosa-5,11,14-trienoic acid

Semiplenamides A

(2E,6E)-N-(2-Hydroxyethyl)-2-methylicosa-2,6-dienamide

Semiplenamides B

2-[[(2E,6E)-2-Methylicosa-2,6-dienoyl]amino]ethyl acetate

Semiplenamides G

2-[[(2S,3R)-2-Methyl-3-pentadecyloxirane-2-carbonyl]amino] propyl acetate

M. Wt.: 314.33 [g/mol]

M. formula: $\mathrm{C}_{18} \mathrm{H}_{18} \mathrm{O}_{5}$ XLogP3-AA: 3.4

H-bond donor/acceptor: 2/5

M. Wt.: 300.349 [g/mol]

M. formula: $\mathrm{C}_{18} \mathrm{H}_{20} \mathrm{O}_{4}$ XLogP3-AA: 4.1

H-bond donor/acceptor: $1 / 4$

M. Wt.: 293.40 [g/mol]

M. formula: $\mathrm{C}_{17} \mathrm{H}_{27} \mathrm{NO}_{3}$ XLogP3-AA: 4.2

H-bond donor/acceptor: $2 / 3$

M. Wt.: 301.27 [g/mol]

M. formula: $\mathrm{C}_{16} \mathrm{H}_{13} \mathrm{O}_{6}{ }^{+}$

H-bond donor/acceptor: 4/5
M. Wt.: 271.24 [g/mol]

M. formula: $\mathrm{C}_{15} \mathrm{H}_{11} \mathrm{O}_{5}{ }^{+}$ H-bond donor/acceptor: 4/4

M. Wt.: 364.77698 [g/mol]

M. formula: $\mathrm{C}_{18} \mathrm{H}_{17} \mathrm{ClO}_{6}$ XLogP3-AA: 3.4

H-bond donor/acceptor: 2/6

M. Wt: 306.48 [g/mol]

M. formula: $\mathrm{C}_{20} \mathrm{H}_{34} \mathrm{O}_{2}$ XLogP3-AA: 6.7

H-bond donor: $1 / 2$

M. Wt.: 365.59 [g/mol]

M. formula: $\mathrm{C}_{23} \mathrm{H}_{43} \mathrm{NO}_{2}$ XLogP3-AA: 7.7

H-bond donor/acceptor: 2/2

M. Wt.: 407.62 [g/mol]

M. formula: $\mathrm{C}_{25} \mathrm{H}_{45} \mathrm{NO}_{3}$ XLogP3-AA: 8.3

H-bond donor/acceptor: $1 / 3$

M. Wt.: 411.61 [g/mol]

M. formula: $\mathrm{C}_{24} \mathrm{H}_{45} \mathrm{NO}_{4}$ XLogP3-AA: 7.6

H-bond donor/acceptor: $1 / 4$
N-Vanillyl pelargonamide, pelargonic acid vanillylamide

(2S)-5,7-Dihydroxy-2-(4methoxyphenyl)-6,8-dimethyl2,3-dihydro-4H-chromen-4-one

3',5'-Dimethoxy-3,4',5,7tetrahydroxy flavylium acid anion

3,4' $, 5,7-$ Tetrahydroxy-3' methoxyflavylium

3,4',5,7-Tetrahydroxy flavylium chloride

Monorderne, radisico, melanotetan II, monorden A

Icosa-5,11,14-trienoic acid, 5c,11c,14c-eicosatrienoic acid 
TABle 1: Continued.

\begin{tabular}{|c|c|c|}
\hline Molecule \& IUPAC name & Chemical properties & Common name(s) \\
\hline $\begin{array}{l}\text { Serinolamide A } \\
\text { (E)-N-[(2R)-1-Hydroxy-3-methoxypropan-2-yl]-N- } \\
\text { methyloctadec-4-enamide }\end{array}$ & $\begin{array}{l}\text { M. Wt.: } 383.6083 \text { [g/mol] } \\
\text { M. formula: } \mathrm{C}_{23} \mathrm{H}_{45} \mathrm{NO}_{3} \\
\text { XLogP3-AA: } 6.6 \\
\text { H-bond donor/acceptor: } 1 / 3\end{array}$ & $\begin{array}{l}(4 \mathrm{E})-\mathrm{N}-[(2 \mathrm{R})-1-H y d r o x y-3- \\
\text { methoxy-2-propanyl]-N-methyl- } \\
\text { 4-octadecenamide }\end{array}$ \\
\hline Voacamine & $\begin{array}{l}\text { M. Wt.: } 704.89 \text { [g/mol] } \\
\text { M. formula: } \mathrm{C}_{43} \mathrm{H}_{52} \mathrm{~N}_{4} \mathrm{O}_{5} \\
\text { XLogP3-AA: } 6.1 \\
\text { H-bond donor/acceptor: } 2 / 7\end{array}$ & Voacanginine, voacamine \\
\hline $\begin{array}{l}\text { Yangonin } \\
\text { 4-Methoxy-6-[(E)-2-(4-methoxyphenyl)ethenyl]pyran-2-one }\end{array}$ & $\begin{array}{l}\text { M. Wt.: } 258.26 \text { [g/mol] } \\
\text { M. formula: } \mathrm{C}_{15} \mathrm{H}_{14} \mathrm{O}_{4} \\
\text { XLogP3-AA: } 2.7 \\
\text { H-bond donor/acceptor: 0/4 }\end{array}$ & $\begin{array}{l}\text { 4-Methoxy-6- }(\beta \text { - }(\mathrm{p} \text { - } \\
\text { anisyl)vinyl })-\alpha \text {-pyrone }\end{array}$ \\
\hline
\end{tabular}

The XLogP3-AA data, molecular weight, molecular formula, and H-bond donor/H-bond were collected from NCBI, http://www.ncbi.nlm.nih.gov/pccompound/?term.

TABLE 2: The cannabinoid receptor affinity, potency, and activity of lead molecules.

\begin{tabular}{|c|c|c|c|}
\hline Compound & $\mathrm{CB}$ receptor mediated effect & $\mathrm{CB}$ receptor affinity/potency & References \\
\hline$\gamma$-Sanshool & Diabetes & $\mathrm{CB}_{2}$ agonist & Dossou et al. 2013 [106] \\
\hline $4^{\prime}$-O-Methylhonokiol & Alzheimer's diseases & $\mathrm{CB}_{2}$ agonist & $\begin{array}{l}\text { Gertsch and Anavi-Goffer 2012 [87] } \\
\text { Schuehly et al. } 2011 \text { [85] }\end{array}$ \\
\hline Yangonin & Anxiety & $\mathrm{CB}_{1}$ receptor antagonist & Ligresti et al. 2012 [112] \\
\hline Amyrin & Neuropathic pain & $\mathrm{CB}_{1} / \mathrm{CB}_{2}$ agonist, MAGL inhibitor & Simão da Silva et al. 2011 [33] \\
\hline Betulinic acid & Cancer & $\mathrm{CB}_{1}$ antagonist $/ \mathrm{CB}_{2}$ agonist & Liu et al. 2012 [38] \\
\hline$\beta$-Caryophyllene & $\begin{array}{l}\text { Ulcerative colitis } \\
\text { Alzheimer's diseases } \\
\text { Insulin resistance } \\
\text { Alcohol addiction } \\
\text { Anxiety } \\
\text { Depression } \\
\text { Nephrotoxicity } \\
\text { Cerebral ischemia }\end{array}$ & $\mathrm{CB}_{2}$ agonist & $\begin{array}{c}\text { Bento et al. } 2011 \text { [40] } \\
\text { Horváth et al. } 2012 \text { [47] } \\
\text { Al Mansouri et al. 2014 [41] } \\
\text { Bahi et al. 2014 [49] } \\
\text { Choi et al. } 2013 \text { [43] } \\
\text { Klauke et al. } 2014 \text { [50] } \\
\text { Suijun et al. } 2014 \text { [44] } \\
\text { Guo et al. 2014 [42] } \\
\text { Gertsch et al. } 2008 \text { [18] }\end{array}$ \\
\hline Celastrol & Neuropathic pain & $\mathrm{CB}_{2}$ agonist & Yang et al. 2014 [55] \\
\hline Chelerythrine & $\begin{array}{l}\text { Neuropathic pain } \\
\text { Neuroblastoma }\end{array}$ & $\mathrm{CB}_{1}$ antagonist & Lim et al. 2003 [57] \\
\hline Curcumin & $\begin{array}{l}\text { Neuroprotective } \\
\text { liver fibrosis }\end{array}$ & $\mathrm{CB}_{1}$ antagonist $/ \mathrm{CB}_{2}$ agonist & $\begin{array}{l}\text { Hassanzadeh and Hassanzadeh, } 2012 \\
{[64]}\end{array}$ \\
\hline Euphol & Neuropathic pain & $\mathrm{CB}_{1} / \mathrm{CB}_{2}$ agonist, MAGL inhibitor & Dutra et al. 2012 [71] \\
\hline $18 \beta$-Glycyrrhetinic acid & Obesity & $\mathrm{CB}_{1}$ antagonist & Park et al. 2014 [73] \\
\hline Pristimerin & Pain \& inflammation & MAGL inhibitor & Chicca et al. 2012 [34] \\
\hline Salvinorin A & $\begin{array}{c}\text { Anxiety } \\
\text { Depression } \\
\text { Neuropathic pain } \\
\text { Ulcerative colitis }\end{array}$ & $\mathrm{CB}_{1}$ agonist, FAAH inhibitor & $\begin{array}{c}\text { Fichna et al. } 2012 \text { [102] } \\
\text { Aviello et al. } 2011[100] \\
\text { Capasso et al. } 2008 \text { [98] } \\
\text { Braida et al. } 2009 \text { [95] } \\
\text { Braida et al. } 2007 \text { [99] }\end{array}$ \\
\hline Malyngamide B & Inflammation & $\mathrm{CB}_{1} / \mathrm{CB}_{2}$ agonist & Montaser et al. 2012 [82] \\
\hline Rutin & Depression & $\mathrm{CB}_{1}$ agonist & Su et al. 2014 [83] \\
\hline Serinolamide B & $\begin{array}{l}\text { Inflammation } \\
\text { Cancer }\end{array}$ & $\mathrm{CB}_{1}$ and $\mathrm{CB}_{2}$ receptors action & Montaser et al. 2012 [82] \\
\hline
\end{tabular}


TABLE 3: The chemical class of compounds showing nature derived cannabinoid ligands.

\begin{tabular}{|c|c|c|c|}
\hline Alkaloids & erpenes and terpenoid & Polyphenols & Fatty acid derivatives \\
\hline $\begin{array}{l}\text { (i) Auroglaucin } \\
\text { (ii) Chelerythrine } \\
\text { (iii) Guineensine } \\
\text { (iv) Bibenzyls } \\
\text { (v) Isoperrottetin A } \\
\text { (vi) Sanguinarine } \\
\text { (vii) } \gamma \text {-Sanshool } \\
\text { (viii) Voacamine } \\
\text { (ix) 3,6-Oxidovoacangine } \\
\text { (x) } \\
\text { 5-Hydroxy-3,6-oxidovoacangine } \\
\text { (xi) Haplosamates } \\
\text { (xii) Desulfohaplosamates } \\
\text { (xiii) Piperine } \\
\text { (xiv) Neocosmosins } \\
\text { (xv) Monocillins } \\
\text { (xvi) Radicicol } \\
\text { (xvii) Yangonin }\end{array}$ & $\begin{array}{l}\text { (i) Amyrin } \\
\text { (ii) Betulinic acid } \\
\text { (iii) } \beta \text {-Caryophyllene } \\
\text { (iv) Celastrol } \\
\text { (v) Euphol } \\
\text { (vi) Falcarinol } \\
\text { (vii) } 18 \beta \text {-Glycyrrhetinic acid } \\
\text { (viii) Isoperrottetin A } \\
\text { (ix) Pristimerin } \\
\text { (x) Salvinorin A } \\
\text { (xi) Thujone } \\
\text { (xii) Yangonin } \\
\text { (xiii) Thujone }\end{array}$ & $\begin{array}{l}\text { (i) Biochanin A } \\
\text { (ii) Curcumin and derivatives } \\
\text { (iii) Cyanidin derivatives } \\
\text { (iv) Desmodianones } \\
\text { (v) Delphinidin } \\
\text { (vi) (+)-Catechin derivatives } \\
\text { (vii) Honokiol derivatives } \\
\text { (viii) Peonidin } \\
\text { (ix) Pelargonidin } \\
\text { (x) Magnolol } \\
\text { (xi) Malvidin } \\
\text { (xii) Rutin } \\
\text { (xiii) 6-Methyltetrapterol A } \\
\text { (xiv) Magnolol } \\
\text { (xv) Miconioside } \\
\text { (xvi) Resveratrol }\end{array}$ & $\begin{array}{l}\text { (i) Dodeca-2E,4E, } 8 Z, 10 Z \text {-tetraenoic } \\
\text { acid isobutylamide } \\
\text { (ii) Dodeca-2E,4E-dienoic acid } \\
\text { isobutylamide } \\
\text { (iii) } 1 \text {-[(2E,4E, } 8 Z) \text {-Tetradecatrienoyl] } \\
\text { piperidine } \\
\text { (iv) Dodeca-2E,4E-dienoic acid } \\
\text { isobutylamide } \\
\text { (v) Tetradeca-2E,4E-dienoic acid } \\
\text { isobutylamide } \\
\text { (vi) Tetradeca-2E,4E,8Z-trienoic acid } \\
\text { isobutylamide } \\
\text { (vii) 1-[(2E,4E,8Z)-Tetradecatrienoyl] } \\
\text { piperidine } \\
\text { (viii) Malyngamides } \\
\text { (ix) Serinolamides } \\
\text { (x) Sciadonic acid } \\
\text { (xi) Semiplenamides }\end{array}$ \\
\hline
\end{tabular}

The study showed that it did not bind to cannabinoid receptors $\left(K_{i}>10 \mu \mathrm{M}\right)$ whereas it inhibited 2-AG hydrolysis in pig brain homogenates and failed to inhibit AEA. Additionally, $\beta$-amyrin is found to weakly inhibit human MAGL in a rapid, reversible, and noncompetitive manner, similar to structurally related but more potent triterpene, pristimerin. Subsequently, Matos et al. [35] also showed the cannabimimetic activity of $\alpha, \beta$-amyrin in dextran sulfate sodium-induced colitis in mice by diminishing disease activity, colonic damage, and activity of myeloperoxidase, Nacetylglucosaminidase, and attenuating induction of proinflammatory mediators: cytokines, chemokines, and adhesion molecules in the colon. The abrogation of the beneficial effects of $\alpha, \beta$-amyrin by $\mathrm{CB}_{1}$ receptor blocker, but not by $\mathrm{CB}_{2}$ receptor blocker, demonstrates the $C_{1}$ receptor mediated mechanism. Additionally, $\alpha, \beta$-amyrin treatment reduced the MAGL and FAAH enzymes. Integrating the ECS modulatory properties $\alpha, \beta$-amyrin seem to be a promising candidate for future therapeutics.

2.3. Anthocyanins. Anthocyanins are water-soluble polyphenol compounds abundantly found in colored fruits and vegetables particularly in red and blue fruits such as blueberry, cranberry, and red cabbage. These have been shown to regulate several intracellular functions. Numerous studies have shown that anthocyanins and anthocyanidins exhibit antioxidant, redox-inflammatory signaling which contributes to its analgesic, cardioprotective, neuroprotective, anticancer, atherogenic, antihyperlipidemic, and antihypertensive effects. The cannabinoid receptor activity has been demonstrated by competitive radioligand assays of cyanidin $\left(K_{i}=16.2 \mu \mathrm{M}\right)$ and delphinidin $\left(K_{i}=21.3 \mu \mathrm{M}\right)$ for $\mathrm{hCB}_{1}$ receptors whereas similar affinities for $\mathrm{CB}_{2}$ receptors have been shown by cyanidin $\left(K_{i}=33.5 \mu \mathrm{M}\right)$, delphinidin $\left(K_{i}=\right.$ $34.3 \mu \mathrm{M})$, and peonidin $\left(K_{i}=46.4 \mu \mathrm{M}\right)$ [36]. However, the cyanidin derivatives such as cyanidin-3,5-di-O-glucoside,
cyanidin-3-O-glucoside, cyanidin-3-O-galactoside, cyanidin-3-O-rutinoside, malvidin, and pelargonidin showed inhibition of both $\mathrm{CB}_{1}$ and $\mathrm{CB}_{2}$ receptors. Additionally, cyanidin-3-O- $\beta$-glucoside also reported to activate all forms of PPARs and reduces hepatic lipids by altering the expression of genes involved in lipid metabolic pathways. Taking altogether the multiple pharmacological properties, anthocyanins appear as polypharmacological agent for diseases involving dysregulation of ECS and PPARs [36].

2.4. Auroglaucin. Auroglaucin, a benzaldehyde compound, is obtained from ethyl acetate extract of fungus Eurotium repens collected from Tifton, GA. The extract as well as auroglaucin showed binding affinity for $\mathrm{CB}_{1}(62.6 \%)$ and $\mathrm{CB}_{2}$ receptors (43.1\%) using CP55,940 assay in CHO-K1 cells [37]. The extract also showed affinity with opioid receptors with binding affinity more than $40 \%$. The $\mathrm{IC}_{50}$ for $\mathrm{CB}_{1}$ and $\mathrm{CB}_{2}$ receptor was 15.2 and $19.9 \mu \mathrm{M}$, respectively [37].

2.5. Betulinic Acid. Betulinic acid is a widely distributed pentacyclic triterpenoid with a lupan skeleton in the plant kingdom. Betulinic acid isolated from the extract of several plants and its synthetic analogues exhibit a broad spectrum of activities including antioxidant, anti-inflammatory, antiangiogenic, immunomodulatory, and anticancer. Liu et al. [38] investigated the effects of $\mathrm{CB}_{1}$ and $\mathrm{CB}_{2}$ receptor antagonists AM251 and AM630, respectively, on betulinic aciddependent repression of Sp1, Sp3, and Sp4 and survivin. Betulinic acid and either AM251 or AM630 attenuated the effects of betulinic acid persuaded downregulation of Sp1, Sp3, and Sp4 and survivin and AM251 and AM630 inhibited betulinic acid-mediated downregulation of ErbB2, p-ErbB2, p-MAPK, p-Akt, and YY1 in BT474 and MDA-MB-453 cells. Further, betulinic acid competitively bound to both cannabinoid receptors with $K_{i}$ values of $36.7 \pm 4.1$ and $41.2 \pm$ $12.1 \mu \mathrm{mol} / \mathrm{L}$ for $\mathrm{mCB}_{1}$ and $\mathrm{hCB}_{2}$ receptors, respectively, in 
radioligand binding assay. The role of $\mathrm{CB}$ receptor mediated activity was further confirmed in $\mathrm{CB}_{1}$ and $\mathrm{CB}_{2}$ knockdown mice partially reversed betulinic acid-induced downregulation of Sp1, Sp3, and Sp4. Betulinic acid-mediated repression of Sp1, Sp3, Sp4, and Sp-regulated genes found because of induction of the Sp repressor ZBTB10 and downregulation of microRNA-27a, which constitutively inhibits ZBTB10 expression, showed that the effects of betulinic acid were $\mathrm{CB}_{1}$ and $\mathrm{CB}_{2}$ receptor dependent. Further, it has also been shown to activate PPAR- $\gamma$, which encourages it as a multitargeted agent for future therapeutics.

2.6. Biochanin A. Biochanin A is an O-methylated isoflavone compound predominantly found in vegetable plants, red clover, soy, alfalfa sprouts, peanuts, and chickpea, and possesses potent antioxidant, anti-inflammatory, phytoestrogenic, and antineoplastic activities. It showed modest effects on $\mathrm{CB}_{1}$ and $\mathrm{CB}_{2}$ receptors in $\left[{ }^{3} \mathrm{H}\right] \mathrm{CP} 55,940$ assay and inhibited brain $\mathrm{CB}_{1}$ receptors $(27 \%)$ and recombinant $\mathrm{CB}_{2}$ receptors (33\%) [39]. No studies are available to demonstrate its other activities such as PPAR- $\gamma$ modulation. It has been reported to inhibit FAAH $\left(\mathrm{IC}_{50}=0.62 \mu \mathrm{M}\right)$ at micromolar potencies in RBL2H3 cells [39].

2.7. $\beta$-Caryophyllene. $\beta$-Caryophyllene, a volatile sesquiterpene, is abundantly found in essential oil of many plants such as cloves, oregano, cinnamon, black pepper, hemp, rosemary, and hops [18]. It is popularly used in food, cosmetics, and fragrances as a preservative, additive, and flavoring agent. It is approved by several food and flavor regulatory agencies including United States Food and Drug Administration (FDA) for its use as a food additive and classified as a "generally regarded as safe" compound. Gertsch et al. [18] first time reported that the fractionation of cannabis essential oil yields $\beta$-caryophyllene which possesses an affinity for $\mathrm{CB}_{2}$ receptors. In radioligand assays, $(E)-\beta$-caryophyllene and its isomer $(Z)$ - $\beta$-caryophyllene dose-dependently displaced CP55,940 from $\mathrm{hCB}_{2}$ receptors significantly expressed in HEK293 cells $\left(K_{i}=155 \pm 4 \mathrm{nM}\right)$ in the nanomolar range and exhibit selective full agonism on $\mathrm{CB}_{2}$ receptors. $(\mathrm{E})-\beta$ caryophyllene exerts potent cannabimimetic anti-inflammatory effects in mice. Several studies have shown the $\mathrm{CB}_{2}$ receptor dependent therapeutic effects in ulcerative colitis [40], alcohol addiction [41], cerebral ischemia [42, 43], insulin resistance [44], glutamate neurotoxicity [45], hypertriglyceridemia [46], renal injury [47], liver fibrosis [48], anxiety and depression [49], neuropathic pain [50], Alzheimer's disease [51], and $\mathrm{CB}_{2}$ receptor knockout mice [47]. Taking together the cannabimimetic [18], opioidergic [52], and PPARs mediated activity [53], $\beta$-caryophyllene appears as most promising molecule of pharmaceutical interest with multifunctional and polypharmacological properties.

2.8. Catechins. Catechins are the group of polyphenol compounds abundantly found in the leaves of tea, the most popular beverage consumed worldwide and in many fruits and legumes. Catechins are known to maintain heath and general well-being and pharmacotherapeutic effects.
The catechin compounds include (-)-epigallocatechin-3O-gallate (EGCG), (-)-epicatechin-3-O-gallate (ECG), (-)epigallocatechin (EGC), (-)-epicatechin, and (+)-catechin. These compounds have been comprehensively studied and shown to possess antioxidant, anti-inflammatory, GABAergic, glutamatergic, monoaminergic, opioidergic, and nitrergic modulatory activities and contribute to the several therapeutic benefits. For the first time, Korte et al. [54] evaluated the affinities of EGCG, ECG, EGC, (-)-epicatechin, and (+)catechin for human $\mathrm{CB}_{1}$ and $\mathrm{CB}_{2}$ receptors in competitive radioligand binding assays in Chem-1 and $\mathrm{CHO}$ cells. All the compounds, namely, EGCG $\left(K_{i}=33.6 \mathrm{mM}\right)$, EGC $\left(K_{i}=\right.$ $35.7 \mathrm{mM})$, and ECG $\left(K_{i}=47.3 \mathrm{mM}\right)$ exhibited binding with $\mathrm{CB}_{1}$ and $\mathrm{CB}_{2}$ receptors in a dose-dependent manner. However, the weaker binding to $\mathrm{CB}_{2}$ receptor was found with inhibition constants more than $50 \mathrm{mM}$ for ECC and EGC. The epimers such as $(+)$-catechin and (-)-epicatechin in radioligand assays showed slight affinities for both $\mathrm{CB}_{1}$ and $\mathrm{CB}_{2}$ receptors. The study demonstrates that catechins possess a moderate affinity for $\mathrm{CB}_{1}$ receptors whereas binding to $\mathrm{CB}_{2}$ receptor was not very prominent. In SAR studies, the ungallated catechins were found to have negligible bioactivities for $\mathrm{CB}_{1}$ and $\mathrm{CB}_{2}$ and the $3^{1}, 4^{1}, 5^{1}$-trihydroxyl substitution in the catechin B-ring partially contributing to antioxidant, apoptosis-inducer, and $\beta$-secretase inhibiting activity of catechins did not appear responsible for binding with cannabinoid receptors. Thus, the multifunctional effects of catechins could be further exploited for cannabinoid activities that with additional pharmacological properties may synergize the actions.

2.9. Celastrol. Celastrol, a quinone methide triterpenoid, is a pharmacologically active constituent from the root of Tripterygium wilfordii and Celastrus regelii (family: Celastraceae) also known as Thunder of God Vine in the Asian continent. It is used as a remedy of inflammatory and autoimmune diseases along with its antioxidant, anti-inflammatory, anticancer, and insecticidal activities. Celastrol showed cannabinoid mediated therapeutic activity in inflammatory and neuropathic pain induced by carrageenan and spared nerve injury in animal models [55]. It produces a dosedependent inhibition of edema and allodynia evidenced by inhibition of inflammatory cytokines and hypersensitivity of nociceptive response. Further, the reversal of antihyperalgesic effects of celastrol by SR144528, a specific $\mathrm{CB}_{2}$ receptor antagonist, but not by SR141716, a specific $\mathrm{CB}_{1}$ receptor antagonist, demonstrates the analgesia effects of celastrol through $\mathrm{CB}_{2}$ signaling. Although celastrol shows an effect on $\mathrm{CB}_{2}$ receptors in neuropathic pain and inflammation, further studies would explore its potential as a novel candidate for pain relief.

2.10. Chelerythrine and Sanguinarine. Chelerythrine and sanguinarine are the alkaloids of quaternary benzophenanthridine class in several medicinal plants and reported as a potent protein kinase $\mathrm{C}$ (PKC) inhibitor. These compounds showed to modify behavior mediated by $\mathrm{CB}_{1}$ receptors [56]. The $\mathrm{CB}_{1}$ receptor modulatory property of chelerythrine was first reported in a chronic constriction sciatic nerve injury 
model of neuropathic pain [57]. The application of chelerythrine was found to inhibit $\mathrm{CB}_{1}$ receptors mainly within the ipsilateral superficial spinal cord dorsal horn mediating tyrosine kinase receptors. Chelerythrine also inhibits desacetyl levonantradol-dependent activation of $\mathrm{CB}_{1}$ receptor in the neuroblastoma cells (N18TG2) and this was supported with modulation of a downstream $\mathrm{PKC}$ by $\mathrm{CB}_{1}$ receptor [58]. The pseudobase forms of chelerythrine and sanguinarine inhibit $\mathrm{CB}_{1}$ receptors similar to $\Delta^{9}$-THC at low micromolar concentrations in mouse brain membrane [59]. In $\left.{ }^{3} \mathrm{H}\right] \mathrm{CP} 55,940$ binding assay, the $\mathrm{IC}_{50}$ of sanguinarine and chelerythrine appears in the $1-2 \mu \mathrm{M}$ range, which has similar potency like cannabidiol, virodhamine, various $\Delta^{8}$-THC derivatives, and certain bicyclic resorcinols [60]. However, these were found weaker than $\Delta^{9}$-THC and $\Delta^{9}$-tetrahydrocannabivarin, which inhibit the binding of $\left[{ }^{3} \mathrm{H}\right] \mathrm{CP} 55,940$ at low nanomolar concentrations [61]. Chelerythrine and sanguinarine showed lesser potency in comparison with several conventional $\mathrm{CB}_{1}$ receptor blockers but act differently to AM251 by the reverse modulation of $\mathrm{CB}_{1}$ receptors [56]. A recent study showed that chelerythrine produces the sequential activation of muscarinic $\left(\mathrm{M}_{3}\right)$ receptors and $\mathrm{CB}_{1}$ receptors which synergistically induce contractile effects of the bovine ciliary muscle by involving the activation of Rho-kinase and PKC [62]. Considering the $\mathrm{CB}$ selectivity these molecules may serve as a template for potent $\mathrm{CB}_{1}$ receptor blocking drugs of natural origin negatively regulating the ECS.

2.11. Curcumin. Curcumin, chemically known as diferuloylmethane, is a well-known polyphenol molecule and an active constituent of the dietary spice turmeric (Curcuma longa) used for dietary and medicinal purposes since centuries. Numerous studies demonstrate that curcumin regulates various signaling molecules including inflammatory molecules, cytokines and chemokines, adhesion molecules, transcription factors, enzymes, protein kinases, protein reductases, carrier proteins, cell survival proteins, cell-cycle regulatory proteins, drug resistance proteins, growth factors, receptors, DNA, RNA, and metal ions. Seely et al. [63] first showed that curcumin binds to $\mathrm{CB}_{1}$ receptors with nanomolar affinities and in micromolar affinities with $\mathrm{CB}_{2}$ receptors. Structurally, curcumin also shares structural motifs with some cannabinoid receptor ligands. Further, curcumin has been showed to cause sustained elevation of brain derived nerve growth factor and endocannabinoids in brain region-specific and dose-dependent manner similar to the conventional antidepressant amitriptyline [64]. However, pretreatment with AM4113, a CB 1 receptor neutral antagonist, but not with SR144528, a $\mathrm{CB}_{2}$ receptor antagonist, prevents induction of brain derived nerve growth factors and suggests $\mathrm{CB}_{1}$ receptor mediated ECS as novel targets for curcumin. Recently, Witkin et al. [65] reported that curcumin did not potently alter GTP- $\gamma$-35S binding, which suggests its functional $\mathrm{CB}_{1}$ antagonist $\left(K_{i}=2080 \mathrm{nM}\right)$. Further, curcumin did not prevent the hypothermic effects of the CP55,940 and the anti-immobility effects of curcumin did not occur in $\mathrm{CB}_{1}$ knockout $\left(\mathrm{CB}_{1}^{-1-}\right)$ mice. In a recent study, Zhang et al. [66] demonstrated the cannabinoid mediated antifibrotic activity of curcumin in liver fibrosis induced by carbon tetrachloride. Curcumin treatment upregulated $\mathrm{CB}_{2}$ receptors and downregulated $\mathrm{CB}_{1}$ receptors in hepatic stellate cells and modulated the expression of extracellular matrix (ECM) proteins. The abrogation of inhibition of curcumin effects on ECM expression revealed that inverse agonism/antagonism of $\mathrm{CB}_{1}$ receptors contributed to curcumin inhibition of $\mathrm{ECM}$ expression. Further, in silico studies showed its binding to $\mathrm{CB}_{1}$ receptors with two hydrogen bonds. In a very recent study, bisdemothoxycurcumin, a derivative of curcumin, has been showed to induce apoptosis in activated hepatic stellate stem cells by impairing cellular energetics and downregulating cytoprotective proteins, likely through a mechanism that involves $\mathrm{CB}_{2}$ receptors as evidenced by reversal of the BDMCinduced apoptosis with cotreatment of SR144528, a $\mathrm{CB}_{2}$ antagonist, and confirmed with genetic downregulation of the receptor using $\mathrm{siCB}_{2}$ receptors [67]. The studies conclude that the effects of curcumin in chronic liver disease are mediated by cannabinoid receptors and may offer therapeutic benefits in hepatic fibrosis. Integrated all together, cannabinoid mediated effects of curcumin and well established manifold properties of curcumin; it holds a strong propensity in diseases where ECS is dysregulated.

2.12. Haplosamate. Haplosamate derivatives are first naturally derived cannabinomimetic compound belonging to steroid family representing a new chemical class of cannabinoid receptor ligands. It is a group of steroids including haplosamate A and haplosamate B $[68,69]$. Haplosamate A is a C28 sterol containing seven oxygenated carbons and a rare six-member ether ring connecting $\mathrm{C}-16$ and $\mathrm{C}-23$ with a sulfate group at C-3 as well as a methyl phosphate at C-15. For the first time, it was isolated from a sponge, Xestospongia sp., and later on from other sponges such as Haplosclerida spp. and Cribrochalina spp. [68] and Indonesian marine sponge, Dasychalina spp. (family: Niphatidae). The isolated haplosamate compounds, haplosamate A and desulfohaplosamate, as well as semisynthetic derivatives were screened for the interaction and affinity to cannabinoid receptor. Haplosamate $\mathrm{A}$ and desulfohaplosamate exert opposite effects as haplosamate $\mathrm{A}$ showed significant affinity for $\mathrm{CB}_{1}$ receptor, whereas desulfohaplosamate showed higher affinity for $\mathrm{CB}_{2}$ receptor. The 7-monoacetylated derivative of haplosamate A exhibits affinity to both cannabinoid receptors in comparison with its parent compound. However, acetylation at C-4 or dialdehyde derivative showed the loss of affinity on both $\mathrm{CB}_{1}$ and $\mathrm{CB}_{2}$ receptors.

2.13. Euphol. Euphol, a tetracyclic triterpene alcohol, is the key constituent in the sap of Euphorbia tirucalli L. (family: Euphorbiaceae), a plant grown in Africa and South America, Brazil, and Amazonas. King et al. [70] first reported that euphol inhibits MAGL in a reversible and noncompetitive manner. The SAR studies reveal that euphol is a bioisoester of pristimerin and lacks the quinone methide group and is found devoid of CNS side effects in the tetrad tests, such as deficit locomotor, catalepsy, analgesia, and hypothermia, typical features of cannabinoids. Euphol showed potent immunomodulator and anti-inflammatory effects in animal 
models of ulcerative colitis and autoimmune encephalomyelitis where $\mathrm{CB}_{2}$ receptors play a vital role in pathogenesis [71]. The antihyperalgesic effect of euphol appears similar to the effects caused by $\mathrm{ACEA}$, a $\mathrm{CB}_{1}$ receptor agonist, and JWH$133, \mathrm{a} \mathrm{CB}_{2}$ receptor agonist. The reversal of the antinociceptive effects of euphol on pretreatment with $\mathrm{CB}_{1}$ antagonist AM251 or with $C_{2}$ selective antagonist $A M 630$ showed $C_{1}$ and $\mathrm{CB}_{2}$ receptor dependent mechanisms. Euphol was found efficacious in preventing the neuropathic behavior mediated through the modulation of both $\mathrm{CB}_{1}$ and $\mathrm{CB}_{2}$ receptors. These findings suggest that euphol has excellent potential for use in neuropathic pain and persistent inflammation owing its ability to interact with ECS and is devoid of the CNS adverse effects even at high doses.

2.14. Falcarinol. Falcarinol is a C17-polyacetylene compound with two carbon-carbon triple bonds and two double bonds and possesses a reactive polyyne structure and is found predominantly in carrot, celery, fennel, parsnip, and Gamisans, members of Araliaceae and Apiaceae family. It is a phytoalexin also known as panaxynol and isolated for the first time from Panax ginseng. It showed to bind with both cannabinoid receptors nonselectively but selectively alkylates the $C_{1}$ receptors and induces $C_{1}$ receptor mediated functional signals by covalent and irreversible interaction with the $\mathrm{CB}_{1}$ receptors $\left(K_{i}=0.59 \mu \mathrm{M}\right)$ [72]. Though, falcarinol is not a functional ligand at $\mathrm{CB}_{2}$ receptor as it did not interfere with constitutive or forskolin-stimulated cAMP but appears as a weak partial agonist on $\mathrm{CB}_{2}$ receptor and acting through $\mathrm{G}_{\mathrm{o}}$ signaling [72]. Falcarinol is unstable and upon exposure to sunlight causes the formation of secondary alcohol with the loss of binding affinity to the cannabinoid receptors. Thus, only freshly obtained falcarinol exerts significant cannabinoid receptor binding affinity. Recently, falcarinol showed inverse agonist/antagonism for the $\mathrm{CB}_{1}$ receptors in keratinocytes and causes expression of proallergic chemokines in keratinocytes, the effects similar to rimonabant. Furthermore, a structural analog of falcarinol, pontica epoxide, was found devoid of affinity either for cannabinoid or for opioid receptors [15].

2.15. $18 \beta$-Glycyrrhetinic Acid. $18 \beta$-Glycyrrhetinic acid and its diastereomer $18 \alpha$-GA are the triterpenoid saponins obtained from the roots of Glycyrrhiza glabra L., popularly known as licorice. It is generally used as a natural sweetener and flavoring additive in food and as traditional medicines owing to its antimicrobial, anticancer, and anti-inflammatory properties. The inhibitory activities of licorice extract in $\mathrm{hCB}_{1}$ receptor-expressing Chem-1 cells showed a dosedependent decrease in intracellular $\mathrm{Ca}^{2+}$ levels $\left(\mathrm{IC}_{50}=1.96 \pm\right.$ $0.05 \mu \mathrm{M}$ ) [73]. Other active constituents of licorice like liquirtin, glabridin, and $18 \alpha$-glycyrrhetinic acid also exhibited inhibitory activity against $\mathrm{Ca}^{2+}$ flux induced by AEA, whereas $18 \beta$-glycyrrhetinic acid showed stronger potency evidenced by more than $90 \%$ inhibition in responses to $\mathrm{CB}_{1}$ receptor agonist. The $18 \beta$-glycyrrhetinic acid was also found to regulate $\mathrm{CB}_{1}$ receptors implicated in antiadipogenesis responses in 3T3-L1 cells and exerts antiobesity effects by correcting lipid dysregulation, body weight gain in diet-induced obese animals [73]. Further, it also alleviated effects of AEA, a $\mathrm{CB}_{1}$ receptor agonist, and suppressed adipocyte differentiation in 3T3-L1 cells by downregulating the AEA-induced MAPK activation and expression of adipogenic genes including C/EBP- $\alpha$ and PPAR- $\gamma$. The $18 \beta$-glycyrrhetinic acid in licorice extract appears to be an active constituent possessing $\mathrm{CB}_{1}$ receptor downregulatory effect and confers therapeutic effects against obesity.

2.16. Guineensine. Guineensine possesses potent cytotoxic, insect repellents, anti-inflammatory, insecticidal, and antifeedant activities from black pepper, Piper nigrum (family: Piperaceae). It appears as a potent novel inhibitor $\left(\mathrm{EC}_{50}=\right.$ $290 \mathrm{nM})$ of cellular uptake of the AEA and 2-AG [74, 75] in nanomolar range. Though, guineensine did not inhibit the enzyme FAAH or enzyme MAGL or interact with cannabinoid receptors or fatty acid binding protein 5 (FABP5), a major cytoplasmic AEA carrier, or serine hydrolases. The SAR studies suggest the significance of alkyl chain length interconnecting the pharmacophoric isobutylamide and benzodioxol moieties for AEA cellular uptake inhibition. Studies have shown cannabimimetic effects such as catalepsy, hypothermia, reduced locomotion, analgesia, and blockade of the effects by $\mathrm{CB}_{1}$ receptor antagonist, rimonabant (SR141716A) in animals. Other common constituents of black pepper, piperine, dose-dependently reduce intestinal fluid accumulation induced by castor oil and pretreatment with SR141716A; a $C_{1}$ receptor antagonist showed that the effects were not dependent on cannabinoid receptors [76]. Similarly, Izzo et al. [77] studied the effect of capsaicin, piperine, and anandamide on upper gastrointestinal motility in mice and showed the inhibitory effect of anandamide but not piperine using a noneffective dose of SR141716A, a $\mathrm{CB}_{1}$ receptor antagonist. Piperine appears to reduce upper gastrointestinal motility independent of $\mathrm{CB}_{1}$ receptors. Guineensine appears as a novel plant derived compound which inhibits endocannabinoid uptake independent of FAAH [74, 75]. Thus, the scaffold of guineensine could be useful in finding future tools for ECS transport and modulatory mechanism in therapeutics.

2.17. Hydroxyeicosatetraenoic Acid (HETE) and HydroxylAnandamide (HAEA). The oxylipin, 3-hydroxyarachidonic acid $(3(R)$-HETE), is an intermediate of the $\beta$-oxidation of arachidonic acid and plays an important biological role in the life cycle of fungi. The fungal pathogen Candida albicans transforms arachidonic acid into 3(R)-HETE. It has been showed that Diposascopsis uninucleata converts AEA into 3-HAEA and established an enantiodivergent synthesis to study its pharmacological activity [78]. The affinity of AEA, $3(R)$-HAEA, and $3(S)$-HAEA for $\mathrm{CB}_{1}$ receptors was $0.02 \pm$ $0.015 \mu \mathrm{M}, 1.85 \pm 0.275 \mu \mathrm{M}$, and $1.46 \pm 0.33$ and for $\mathrm{CB}_{2}$ receptors was $0.11 \pm 0.025 \mu \mathrm{M}, 6.43 \pm 0.7710 \mu \mathrm{M}$, and $4.85 \pm$ $0.38 \mu \mathrm{M}$, respectively. Thus, yeasts producing $3(R)-\mathrm{HETE}$ convert AEA released by the host cells at the site of infection into 3(R)-HAEA which leads to the inflammatory and algogenic responses associated with fungal diseases. Both the enantiomers of 3-HAEA exhibited similar affinity for $\mathrm{hCB}_{1}$ 
and $\mathrm{hCB}_{2}$ receptors but significantly (approximately 7090 -fold and approximately 40-60-fold) lower affinity than the parent compound AEA. Further, studies are needed in order to utilize these compounds in drug discovery through biotransformation.

2.18. Magnolol. Magnolol, a biphenyl neolignan from Magnolia officinalis, was used popularly in traditional Chinese medicine for insomnia, anxiety, and allergic diseases. Rempel et al. [79] examined the extract and biphenyls honokiol, magnolol, 8,9-dihydromagnolol, tetrahydromagnolol, and trans-isomagnolol for its cannabinoid affinity and activity. The study showed that magnolol behaved as partial agonist for $\mathrm{CB}_{2}$ receptor, while honokiol was less potent but showed full agonistic activity at $\mathrm{CB}_{1}$ and antagonistic properties at $\mathrm{CB}_{2}$ receptor. However, further studies showed no inhibition activity for FAAH and MAGL in rat brain preparations. Thus magnolol showed partial agonist affinity at both CB receptor subtypes, while tetrahydromagnolol showed higher affinity for $\mathrm{CB}_{2}$ receptor and antagonist at GPR55, a CB-related orphan receptor in $\beta$-arrestin translocation assays.

Fuchs et al. [80] synthesized analogs of magnolol and investigated affinity at $\mathrm{hCB}_{1} / \mathrm{CB}_{2}$ receptors using $\mathrm{CP} 55,940$ radioligand studies and also examined $\mathrm{SAR}$ of these analogs with variations of alkyl chains and phenolic groups which may improve the potency. The study showed that methylation of phenolic hydroxyl group abolishes the preference of magnolol analogs for $\mathrm{CB}_{2}$ receptors; however depending on which of the two phenolic groups was methylated the resulting compounds exhibited an enhanced affinity to $\mathrm{CB}_{1}$ receptors. Full agonism on $\mathrm{CB}_{1}$ and $\mathrm{CB}_{2}$ receptors was observed following methylation of the hydroxyl group in the para-position to the propyl residue for derivatives. But methylation of the hydroxyl group in the para-position of the hexyl residues results in $\mathrm{CB}_{1}$ antagonist and partial $\mathrm{CB}_{2}$ receptors agonist activity, emphasizing the importance of the free phenolic hydroxyl group for high intrinsic activity. Further, activity of new analogs at $\mathrm{G}_{\mathrm{i}}$-coupled $\mathrm{CB}_{1}$ and $\mathrm{CB}_{2}$ receptor subtypes on forskolin-stimulated adenylate cyclase activity in cAMP accumulation assays confirmed that potency and efficacy of magnolol can be easily altered by methylation of one of the phenolic hydroxyl groups and depending on the position of the methoxy group, full agonism on both receptors with antagonist activity at $\mathrm{CB}_{1}$ and partial agonist activity at $\mathrm{CB}_{2}$ receptors can be achieved. Magnolol also exhibited dual agonism of $\operatorname{RXR} \alpha$ and $\operatorname{PPAR} \beta / \gamma$ and appears as an important agent to target this heterodimer [81]. The manipulation of the biphenyl scaffold appears as a putative pharmacophore for the further development of novel $\mathrm{CB}$ receptor ligands.

2.19. Malyngamides. Malyngamides are the fatty acid amide compounds abundantly found in marine cyanobacterial metabolites from Lyngbya spp. Till date, more than 30 malyngamide analogues have been isolated and screened for their cannabinoid affinity and activity. Among numerous analogues, malyngamide $\mathrm{B}$ appeared to bind to both $\mathrm{CB}_{1}$ and $\mathrm{CB}_{2}$ receptors, with moderate potencies as agonist. Further tests reveal its anti-inflammatory properties like cannabimimetic compounds and it was found to inhibit $\mathrm{NO}$ production with an $\mathrm{IC}_{50}$ of $6.2 \mu \mathrm{M}$ without affecting cellular viability up to $25 \mu \mathrm{M}$. It appears devoid of inhibitory activity on FAAH, which catalyzes anandamide hydrolysis and terminates anandamide signaling [82].

2.20. Rutin. Rutin is a flavonoid from Saussurea involucrata also known as snow lotus, in different regions of China. The cannabinoid mediated antidepressant activity of rutin shown in mice models employing weight-loaded forced swim test. Rutin treatment showed upregulation of $\mathrm{CB}_{1}$ receptors in mouse brain tissue demonstrating antifatigue activity and $\mathrm{CB}_{1}$ receptor-interacting proteins. Further, in brain tissues, an increase in expression of peroxisome proliferatoractivated receptor- $\alpha$ coactivator (PGC- $1 \alpha$ ) and sirtuin 1 (SIRT1) was also demonstrated [83]. Integrating together the cannabinoid, PPAR- $\gamma$, and opioid receptor activities, rutin may be a potential multitargeted polypharmacological agent in prevention and treatment of diseases involving dysregulation of PPAR and ECS.

2.21. Serinolamides. Serinolamides are fatty acid amides found in a marine cyanobacterium, Lyngbya spp., collected from Piti Bomb Holes from Guam. Among the isolated compounds, the analogue serinolamide $\mathrm{A}$ isolated from the marine cyanobacterium, Lyngbya majuscula, Oscillatoria spp., showed structural similarity to the endocannabinoids anandamide and 2-AG. Serinolamide A showed binding affinity to the human cannabinoid receptors and found 5fold more selective agonist activity for the $\mathrm{CB}_{1}$ receptors with moderate binding affinity [84], whereas serinolamide B appeared to inhibit forskolin-stimulated cAMP accumulation mediating both $\mathrm{CB}_{1}$ and $\mathrm{CB}_{2}$ receptors with moderate potencies along with more $\mathrm{CB}_{2}$ receptor selectivity in binding as well as functional assays. However, serinolamide B showed an opposite trend in binding affinities compared to serinolamide A, where it exhibited a moderate affinity and higher selectivity for $\mathrm{CB}_{2}\left(K_{i}=5.2 \mu \mathrm{M}\right)$ over $\mathrm{CB}_{1}$ receptor $\left(K_{i}=16.4 \mu \mathrm{M}\right)$ [82]. Serinolamide B like other cannabimimetic compounds exerted anti-inflammatory effects in lipopolysaccharide(LPS-) induced murine macrophages RAW 264.7 with an $\mathrm{IC}_{50}>25 \mu \mathrm{M}$. The observations indicate that presence of a secondary amide versus a tertiary amide is not a major element for specific receptor selectivity. Though, the compounds represent a novel scaffold from a marine organism for the development of cannabinoid modulators.

2.22. Methylhonokiol. $4^{\prime}$-O-Methylhonokiol is a polyphenolic compound isolated from Magnolia grandiflora L., a tree growing in Northern Mexico and the USA. Schuehly et al. [85] first reported methylhonokiol as a potent agonist on $\mathrm{CB}_{2}$ receptors, triggering a novel type of heteroactive signaling in the radioligand displacement assays in HEK293 cells. In an in vitro study, methylhonokiol only showed ligand binding interactions with $\mathrm{CB}_{2}$ receptors but no effects on GPR55 and $\mathrm{CB}_{1}$ receptors. It also acts both as inverse agonist and as agonist dependent on the specific signal pathways. A prominent effect of methylhonokiol observed is inhibition of macrophage migration induced by $2-A G$, even though 
it shows anti-inflammatory properties similar to 2-AG and other endocannabinoids [86].

Based on the reports that orally administered $4^{\prime}$-Omethylhonokiol prevents amyloidogenesis and progression of Alzheimer's disease by inhibiting neuroinflammation in mouse model of Alzheimer's disease [87], authors also suggested that $4^{\prime}$-O-methylhonokiol exerts its beneficial effects by modulation of $\mathrm{CB}_{2}$ receptors significantly expressed in astrocytes and microglia. Its structural similarity with HU308, a synthetic $\mathrm{CB}_{2}$ receptor-selective agonist, has been shown to inhibit osteoclastogenesis and be useful as bone resorption inhibitors support its cannabinoid property [88]. Overall, with activities such as GABAergic, PPAR- $\gamma$, and AChE modulatory, methylhonokiol seems to be a novel agent to target $\mathrm{CB}_{2}$ receptors in treatment of osteoarthritis, Alzheimer's disease, neuroinflammation, neuropathic pain, and chronic bowel disease.

2.23. Miconioside. Miconioside compounds are flavanone glycoside isolated from the methanolic extract of the stems of Miconia prasina growing in tropical and subtropical regions of the Americas. These compounds include miconiosides $\mathrm{B}$ and $C$ which showed their affinity to bind with $C_{1}$ and $\mathrm{CB}_{2}$ receptors. They showed weak inhibition for $\mathrm{CB}_{2}$ receptors, but no activity on $\mathrm{CB}_{1}$ receptors in radioligand binding studies [89].

2.24. Pristimerin. Pristimerin is a natural quinone methide triterpenoid isolated from the Celastrus and Maytenus spp. exhibiting anti-inflammatory, antioxidant, chemoprotective, and antimalarial activity. Pristimerin exhibits reversible inhibition of MAGL [70] as the quinone methide group to react with cysteine residues of proteins to form covalent adducts [90] and this was confirmed by using a rapid dilution assay. The molecular docking studies showed that lipophilic portion of the molecule lies on a pocket located within the lid domain of MAGL and its 3-hydroxyl group [70]. The binding of pristimerin to MAGL strengthens by the formation of a polar interaction with a regulatory cysteine, possibly $\mathrm{Cys}^{208}$. Chicca et al. [34] also showed that pristimerin and JZL184 both produce potent inhibition of MAGL activity. Pristimerin produced inhibition of $\left[{ }^{3} \mathrm{H}\right]$-glycerol formation and accumulation of intracellular $\left[{ }^{3} \mathrm{H}\right] 2-\mathrm{AG}$ and was found less potent than $\beta$-amyrin, another MAGL inhibitor. Based on the in vitro and in vivo studies, it has been concluded that pristimerin inhibits MAGL in a rapid, reversible, and noncompetitive manner.

2.25. Resveratrol. Resveratrol is a stilbenoid compound isolated from fruits and plants and widely studied for its pharmacological properties. Recently, the uncharacterized trans-resveratrol receptor has shown to share many characteristics with cannabinoid receptors. The affinity of transarachidins, trans-resveratrol, and trans-piceatannol for $\mathrm{CB}_{1}$ and $\mathrm{CB}_{2}$ receptors was investigated in $\mathrm{CHO}$ cells expressing cannabinoid receptors and it was found that trans-resveratrol and all analogs bind to $\mathrm{CB}_{1}$ receptors, whereas isoprenylated trans-resveratrol derivatives tA1 and tA3 bind to $\mathrm{CB}_{2}$ receptors [63]. The study showed affinity of trans-resveratrol and trans-piceatannol for $\mathrm{CB}_{2}$ receptors is 5- to 10 -fold lower than that observed for $\mathrm{CB}_{1}$ receptors. All compounds except for tA3 exhibit approximately 2- to 10-fold selectively for binding to $C_{1}$ receptors relative to $C_{2}$ receptors. In molecular docking, trans-arachidins, trans-resveratrol, trans-piceatannol, and their glucuronidated metabolites bind with $\mathrm{CB}_{2}$ receptors while isoprenylated analogs $\mathrm{tA} 1$ and $\mathrm{tA} 3$ bind with both $\mathrm{CB}_{1}$ and $\mathrm{CB}_{2}$ receptors. Trans-resveratrol and Trans-picetamol also bind to $\mathrm{mCB}_{1}$ receptors; however they lack affinity for $\mathrm{hCB}_{2}$ receptors. The docking studies showed that prenylated stilbenoids trans-arachidins 1 and 3, the more lipophilic isoprenylated analogs of trans-resveratrol and trans-piceatannol, may be preferable alternatives to trans-resveratrol due to increased bioavailability via slowed metabolism. Both parent and isoprenylated compounds bind to $\mathrm{CB}_{1}$ receptors and were confirmed by the antagonistic actions produced by $\mathrm{CB}_{1}$ receptor agonists. However, the analogs possess an isoprenyl group, trans-arachidin 1 and trans-arachidin 3, showed affinity for $\mathrm{CB}_{2}$ receptors, and were further confirmed by molecular docking [91]. Though, resveratrol has been well investigated in numerous experimental and clinical studies; however the cannabinoid mediated pharmacological effects need to be ascertained.

2.26. Resorcylic Acid Lactones. Resorcylic acid lactones neocosmosin A, neocosmosin B, neocosmosin C, monocillin IV, monocillin II, and radicicol are obtained from ethyl acetate extracts of Neocosmospora spp. The extracts as well as the compounds were found to exhibit moderate affinity with opioid receptor and cannabinoid receptors in a high throughput screen employing a receptor binding assay. Among these compounds, neocosmosin B, monocillin II, and radicicol showed a binding affinity for $\mathrm{CB}_{1}$ receptors using CP55,940 as standard. However, compounds, neocosmosin A, neo$\operatorname{cosmosin} \mathrm{B}$, neocosmosin $\mathrm{C}$, monocillin $\mathrm{II}$, and radicicol, exhibited binding affinity to $\mathrm{CB}_{2}$ receptors with respect to CP55,940 as standard. Neocosmosin C, monocillin II, and radicicol also showed good affinity for binding with the human opioid receptors $[92,93]$. These findings are implicated in neuropathic pain and neuroinflammatory disorders where opioid and cannabinoid systems are dysregulated.

2.27. Salvinorin A. Salvinorin A, a trans-neoclerodane diterpenoid, is the principal constituent of Salvia divinorum, a plant used in Mexico for spiritual and medical purposes. It possesses psychotropic activity that resembles with the structure and mode of action of typical hallucinogens. The radioligand displacement studies show salvinorin $\mathrm{A}$ as a potent, selective, and full agonist on $\kappa$-opioid receptors [9496], but not $\mu$ - or $\delta$-opioid receptors. Other studies have shown that salvinorin A possesses ECS mediated activity and interaction with $\kappa$-opioid in rats and Zebra fish models [94, 96-101]. It provides a new lead compound for developing antiallodynic agents via opioid and $\mathrm{CB}_{1}$ receptors activation. Fichna et al. [102] demonstrated that salvinorin A impedes gastrointestinal motility and ion transport, mediated by $\kappa$ opioid receptors in mice. Further, it significantly attenuated chemical-induced colitis in mice and the antinociceptive 
action was blocked by opioid and $\mathrm{CB}_{1}$ receptor antagonists. Salvinorin A also slows colonic motility in vitro and in vivo and alters neurogenic ion transport $[103,104]$. Further, Fichna et al. [105] reported the inhibitory effects of salvinorin A on endotoxin-induced ileal hypercontractility in mouse stomach mediated by opioid receptors and cannabinoid receptors. The inhibitory effect of salvinorin A on motility demonstrates functional interaction between $\mathrm{CB}_{1}$ and $\kappa$-opioid receptors in the inflamed gut but in normal control animals [98].

Further, Aviello et al. [100] reported that salvinorin A reduced inflammation and pain in animal models of LPS- and carrageenan-induced paw edema as well as formalin-induced inflammatory pain. The actions were found mediated by the $\kappa$-opioid receptors and $\mathrm{CB}_{1}$ receptors-dependent antiinflammatory actions on macrophages and in experimental animals. A study evaluated salvinorin $\mathrm{A}$ in a set of in vitro and in vivo tests and demonstrated that salvinorin $\mathrm{A}$ did not bind or activate $\mathrm{CB}_{1}$ receptors but effects are mediated by its activation of $\kappa$-opioid receptors [96]. Braida et al. [95] reported the anxiolytic- and antidepressant-like effects of salvinorin A which are mediated by both $\kappa$-opioid and $\mathrm{CB}_{1}$ receptors. In addition to a weak affinity for $\mathrm{CB}_{1}$ receptors, it also reduced FAAH activity in amygdale. Based on the cannabinoid and opioid modulatory activity, salvinorin A or its synthetic or semisynthetic derivatives could be useful in the treatment of lower gastrointestinal disorders because inflammation in the intestine upregulates cannabinoid receptors and endogenous cannabinoids.

2.28. $\gamma$-Sanshool. $\gamma$-Sanshool is an alkylamide compound isolated from Zanthoxylum clava-herculis L. (family: Rutaceae) also known as pepperwood, native to the southeastern United States. Dossou et al. [106] have shown its $\mathrm{CB}_{2}$ receptor activity. Subsequently, a novel plate-based assay was developed in order to determine both $\mathrm{CB}_{1}$ and $\mathrm{CB}_{2}$ receptors antagonist and agonist activity and the ligand effect on internalization of the $\mathrm{CB}_{1} / \mathrm{CB}_{2}$ receptors in different extracts of the plant genus Zanthoxylum [106].

Later, it was found that $\gamma$-Sanshool isolated from Zanthoxylum bungeanum shows potent agonism on the $\mathrm{CB}_{2}$ receptor and antagonism on $\mathrm{CB}_{1}$ receptors. In addition to its interactions with $\mathrm{CB}_{1}$ and $\mathrm{CB}_{2}$ receptors, it showed antagonist activity at the follicle stimulating hormone receptor (68\%) and at the prolactin-releasing hormone receptor (52\%). These findings reveal that, given the role of cannabinoid receptors in diabetes pathophysiology, $\gamma$-Sanshool with a dual function on $\mathrm{CB}_{1}$ receptors inhibition in combination with $\mathrm{CB}_{2}$ activation may be useful in the treatment of diabetes.

2.29. Sciadonic Acid. Sciadonic acid is obtained from the seeds of a coniferous plant, Sciadopitys verticillata (umbrella pine) in Japan. Sciadonic acid structurally resembles with 2-AG, the endogenous natural ligand for the cannabinoid receptor. Nakane et al. [107] showed that sciadonic acid exhibits cannabimimetic activity by inducing rise of intracellular $\mathrm{Ca}^{2+}$ levels in neuroblastomaxglioma hybrid cells (NG10815) expressing $\mathrm{CB}_{1}$ receptors. This was the first study showing the occurrence of a cannabimimetic monoacylglycerol in higher plants exhibiting $\mathrm{CB}_{1}$ receptor dependent mechanism.

2.30. Semiplenamides. Semiplenamides (semiplenamide A to $\mathrm{G})$ belong to a series of novel fatty acid amides similar to endocannabinoid, anandamide. These were isolated from marine blue green algae, Lyngbya semiplena collected from Papua New Guinea. Semiplenamides A, B, and G derivatives exhibited weak affinity for the $C_{1}$ receptors [108]. Additionally, semiplenamide A was found to be a moderate inhibitor of the anandamide membrane transporter thereby inhibiting anandamide breakdown. The results indicate that these compounds may appear as future cannabinoid specific drugs of natural origin.

2.31. Thujone. Thujone, a monoterpene ketone, is found in variable amounts in several food and medicinal plants such as Juniperus spp., Cedrus spp. It has been regarded as a severe neurotoxicant causing exciting and convulsive effects in the CNS by inhibiting $\mathrm{GABA}_{\mathrm{A}}$ receptors in a dose-dependent manner. It is known for its notoriety being an important component of the once-popular drink absinthe. Thujone possesses psychoactivity similar to cannabinoids but does not mimic cannabinoids in inhibiting the synaptosomal enzyme [109].

Meschler and Howlett [110] investigated the affinity of thujone for the brain $\mathrm{CB}_{1}$ receptor in radioligand assay and found that thujone affinity with the $\mathrm{CB}_{2}$ receptor is approximately similar to the $\mathrm{CB}_{1}$ receptor. In bioassays and forskolin-stimulated adenylate cyclase assays, thujone did not show any activity on $\mathrm{CB}_{1}$ receptor. Thujone treatment in rats exhibited different behavioral characteristics, the open-field test for locomotor activity, the ring-stand test for immobility (catalepsy), and hot-plate test for antinociception comparable with a potent cannabinoid agonist, levonantradol. Though, thujone was found devoid of stimulatory activity on brain cannabinoid receptors and does not elicit cannabimimetic behavioral effects in animals at physiologically relevant doses.

2.32. Voacamine and Analogues. Voacamine, 3,6-oxidovoacangine, and 5-hydroxy-3,6-oxidovoacangine are the indole alkaloids isolated from methanolic extract of root bark of Voacanga africana, a tropical African tree. Several compounds have been isolated and screened for the cannabinoid activity in Aequorin/GPCR cell-based $\mathrm{Ca}^{2+}$ functional assay using CP55,940 or rimonabant as a positive control for cannabinoid receptors ligands [111]. These compounds exhibited potent $\mathrm{CB}_{1}$ receptor antagonist activity in a concentration-dependent manner compared to rimonabant, whereas the other coexisting alkaloids, such as voacangine, vobasine, and tabersonine, fail to exhibit any $\mathrm{CB}$ receptor mediated activity. This was the first study showing that naturally occurring alkaloids are also source of $\mathrm{CB}_{1}$ receptor antagonists and this could be further evaluated for cannabimimetic activity and potential therapeutic benefits.

2.33. Yangonin. Yangonin is a kavalactone extracted from Piper methysticum Forster, popularly known as Kava, and cultivated in the South Pacific Island Countries. Several 
compounds, known as kavalactones, are isolated and the most common are kavain, 7,8-dihydrokavain, methysticin, 7,8dihydromethysticin, yangonin, and desmethoxyyangonin. Ligresti et al. [112] examined their CB receptor binding affinity and inhibitory activity on endocannabinoid metabolizing enzymes, FAAH and MAGL involved in endocannabinoid degradation. Only yangonin emerged as the most interesting compound as evidenced by the binding affinity to the $\mathrm{CB}_{1}$ receptor $\left(K_{i}=0.72 \mu \mathrm{M}\right)$. However, all other compounds were found inactive in inhibiting activities of FAAH and MAGL enzymes.

The study also reported that $250-1250 \mathrm{mg}$ yangonin, which is $10 \%$ of the total kavalactone-content taken orally, may provide sufficient serum concentrations of yangonin to affect $\mathrm{CB}_{1}$ receptors in the $\mathrm{CNS}$. The authors suggested that yangonin which possesses an extensive conjugated double bond system bears a little structural resemblance to the phytocannabinoids. The kavalactones may also be a target for GABA and BZDs, voltage gated $\mathrm{Na}^{+} / \mathrm{Ca}^{2+}$ channels, monoamine uptake, and arachidonate cascade which may synergize and contribute to the psychopharmacological profile of the Kava.

Miscellaneous Compounds Isolated from Nature. Desmodianone derivatives, desmodianones $\mathrm{D}$ and $\mathrm{E}$ and 6-methyltetrapterol A, are isoflavonoids isolated from Desmodium canum. It is known for soil preserving property and used as forage with some application in traditional medicine. These isoflavonoids possess cannabinoid-like moieties; however no further reports on their cannabimimetic or cannabinoid modulatory activity are available in the literature [113]. Isoperrottetin A, a bibenzyl compound along with several bisbenzyls, prenyl bibenzyls, and sesquiterpenoids, has been isolated from the ether extract of the liverwort, Radula perrottetii. All these compounds are known to structurally consist of cannabinoid moiety; however there is no report available on their ECS modulating property [114].

Leucettamols are the bifunctionalized sphingoid-like compounds obtained from a marine sponge, Leucetta sp. In preliminary studies, they appear inactive on $\mathrm{CB}_{1}, \mathrm{CB}_{2}$, and TRPV1 receptors. Soderstrom et al. [115] also extracted numerous endocannabinoid-like purified unsaturated fatty acids from green algae (Chlorophyta), the brown alga Laminaria angustata, and the sponge Mycale micracanthoxea. The authors did not find endocannabinoid compound from $L$. majuscula. Also, AEA has been detected in dietary chocolate and cocoa obtained from Theobroma cacao, a popular plant [116]. Recently, in a study, several compounds such as sinostrobin, naringenin $7,4^{\prime}$-dimethyl ether, $2^{\prime}, 6^{\prime}$-dihydroxy$4^{\prime}$-methoxychalcone, 4-methoxy-6-(2-phenylethenyl)-2Hpyran-2-one, naringenin 7-methyl ether, and 3,5-heptanediol, 1,7-diphenyl are isolated from the dichloromethane extract of Renealmia alpinia subjected to either opioid or cannabinoid receptors in vitro binding affinity assays. Though, the plants show antinociceptive and analgesic effect in the in vivo model but the constituents and plant failed to show affinity to cannabinoid receptors [117]. The compound isolated from the soil microfungus, Eupenicillium parvum, showed selective $\mu$-opioid receptor and $\mathrm{CB}_{1}$ receptor binding affinities, in vitro binding assays [118]. These findings provide insight into the potential therapeutic utility of this class of compounds.

\section{Medicinal Plants Modulating Cannabinoid Receptors and Metabolizing Enzymes}

In the last few years, several medicinal plants have been reported to modulate the ECS activity by inhibiting or activating the cannabinoid receptors and the endocannabinoid metabolizing enzymes [22]. The plants have been reported to interact with cannabinoid receptors directly or indirectly in experimental studies designed to evaluate the pharmacological properties and therapeutic benefits using pharmacological challenge of $\mathrm{CB}$ receptor agonists and antagonists or utilizing the $\mathrm{CB}_{1} / \mathrm{CB}_{2}$ receptor knockout mice $[6,19,22]$. Several medicinal plants other than cannabis have been shown to alter the ECS signaling pathways and exhibit cannabimimetic effects and put forward their potential therapeutic and dietary application [6, 16-19]. The therapeutic and pharmacological activities presented by these plants involving cannabinoid mediated activity are present in Table 4 .

In the modern era of medicine medicinal plants and phytochemicals derived from plants continue to play an important role in drug discovery and development $[6,16,17$, 41]. The plants have become the key resource for bioactive agents and played a vital role in the search of lead compounds for novel drug discovery and development. The isolated bioactive agents and their synthetic or semisynthetic analogs can be developed into promising drug candidates by the processes of highly efficient bioactivity-directed fractionation and isolation, following analog synthesis using modern medicinal chemistry-based molecular modifications. The next paragraphs focus on medicinal plants other than cannabis which have been reported to interact with the molecular components of ECS and are detailed below. The bioactive constituents of such plants display a rich source for the discovery of novel cannabinoid compounds with potential for pharmacological applications and drug development. Besides the small molecules, secondary metabolites also play an important role in search of novel compounds.

3.1. Corydalis yanhusuo. Corydalis yanhusuo (family: Papaveraceae) is one of the traditional Chinese medicines used as sedative, hypnotic, and pain killer possessing a number of potent alkaloids. The $\mathrm{CB}_{1}$ receptor mediated effect of Corydalis yanhusuo was tested in an animal model of trigeminal neuralgia pain induced in rats by chronic constriction injury of the infraorbital branch of the trigeminal nerve [119]. Corydalis binds to $\mathrm{CB}_{1}$ receptors and exerts antinociceptive effect in animal models of inflammation and pain. In addition, tetrahydropalmatine [127] an active component isolated from Corydalis has shown to improve anxiolysis and decreased motor movements, independent of the $\mathrm{GABA}_{\mathrm{A}}$ receptors [127]. The analgesic and anti-inflammatory effect mediated by $\mathrm{CB}_{1}$ receptors along with anxiolytic activity is an advantage over synthetic $\mathrm{CB}_{1}$ receptor modulators [127].

3.2. Echinacea purpurea. Echinacea purpurea is commonly used worldwide for the prevention and treatment of 
TABLE 4: The cannabinoid receptor affinity, potency, and activity of medicinal plants.

\begin{tabular}{lccc}
\hline Medicinal plants & CB mediated effect & CB affinity/potency & References \\
\hline Corydalis yanhusuo & Neuropathic pain & $\mathrm{CB}_{1}$ antagonist & Huang et al. 2010 [119] \\
Echinacea purpurea & Immunomodulation & $\mathrm{CB}_{2}$ agonist & Chicca et al. 2009 [25] \\
Linum usitatissimum & Inflammation & $\mathrm{CB}_{2}$ agonist & Styrczewska et al. 2012 [120] \\
Melilotus suaveolens & Lung injury & $\mathrm{CB}_{2}$ agonist & Liu et al. 2014 [121] \\
Morinda citrifolia & Immunomodulation & $\mathrm{CB}_{1}$ antagonist/CB $\mathrm{CB}_{2}$ agonist & Palu et al. 2008 [122] \\
Nelumbo nucifera & Obesity & $\mathrm{CB}_{2}$ agonist & Velusami et al. 2013 [123] \\
Olea europaea & Colon cancer & $\mathrm{CB}_{1}$ agonist & Cotrim et al. 2012 [124] \\
Rubus coreanus & Osteoporosis & $\mathrm{CB}_{1}$ antagonist/CB $\mathrm{CB}_{2}$ agonist & Lim et al. 2015 [125] \\
Ruta graveolens & Diabetes & $\mathrm{CB}_{2}$ agonist & Rollinger et al. 2009 [126] \\
\hline
\end{tabular}

common cold, cough, bronchitis, influenza, and allergic respiratory diseases. It has been shown to exert antioxidant, anti-inflammatory, and immunostimulatory properties owing to the chemical constituents, alkamides, and ketoalkenes/alkynes. The alkamides were the first compounds identified in plants besides cannabis to possess cannabimimetic properties on both the cannabinoid $\mathrm{CB}_{1}$ and $\mathrm{CB}_{2}$ receptors, revealing their structural similarity to the endogenous cannabinoid ligand anandamide $[20,128]$. The extract of Echinacea roots was studied in ${ }^{[35 \mathrm{~S}]}$ GTPcSbinding experiments on rat brain membrane preparations using arachidonyl-20-chloroethylamide (ACEA), a full agonist ligand at the $\mathrm{CB}_{1}$ receptor [128]. Among the isolated compounds, some displayed partial agonist property while others exhibit inverse agonist effects to $\mathrm{CB}_{1}$ receptor. Despite their relatively low efficacy at the cannabinoid receptors, the compounds behave as inverse agonist was capable of inhibiting the full agonist effect of ACEA. The compounds showed partial agonistic property that also significantly increased the G-protein-stimulatory action of ACEA. The SAR studies showed an exchange of isobutylamide moiety (inverse agonist activity) of the molecule for 2-methylbutylamide (partial agonist activity).

The $\mathrm{CB}_{2}$ receptor activity of alkamides, demonstrated by binding assays, is believed to be the most probable mechanism of action of alkamides as immunomodulator agents isolated from Echinacea [21, 25, 27, 129]. The interaction between anxiety and cannabinoids is known to be complex and activation of the $\mathrm{CB}_{1}$ receptors by endogenous ligands was believed to play a role in the control of anxiety [128]. The dry and fresh herb of Echinacea provides a different yield of alkamides [29, 30]. All together the studies convincingly suggest that Echinacea could provide scaffolds for future $\mathrm{CB}_{2}$ ligands in drug discovery and development.

3.3. Linum usitatissimum. Linum usitatissimum (family: Linaceae), also known as flax, is considered a distinct source of fibers and oil for industrial and medicinal application. The transgenic plants are generated in order to enhance the production of phenylpropanoids; a class of new terpenoid has shown to possess health-beneficial properties. The plant has shown to alter the expression of genes involved in inflammatory processes in mouse and human fibroblasts and activates the gene expression of $\mathrm{CB}_{2}$ receptor [120]. The findings reveal that flax can be a source of cannabinoidlike compounds which may influence the immunological responses and aid in designing the fabric for wound dressing with putative anti-inflammatory properties [120].

3.4. Melilotus suaveolens. Melilotus suaveolens Ledeb. (family: Leguminosae), a traditional Tibetan medicine, is also known as wild alfalfa or "cold-tasting" annual or biennial herb. It has been reported to contain compounds such as coumarin, flavonoids, phenolic acids, steroids, and triterpenes. It has been found effective in inflammation, pain, and antimicrobial activity. The cannabinoid mediated antiinflammatory activity of $M$. suaveolens has been demonstrated in a rat cecal ligation and puncture- (CLP-) induced animal model of acute lung injury representing sepsis in human [121]. It has shown to upregulate the $\mathrm{CB}_{2}$ expression in peripheral blood mononuclear cells, reduce the number of neutrophils, lymphocytes, and total cells, and inhibit the induction of proinflammatory cytokines and transcription factors, NF- $\kappa \beta 65$. The $\mathrm{CB}_{2}$ expression was shown to be correlated negatively with NF- $\kappa \beta$ mRNA and supported by a significant reduction in CLP-induced lung inflammation. These findings suggest that $M$. suaveolens may have therapeutic potential in the treatment of CLP-induced acute lung injury.

3.5. Morinda citrifolia. Morinda citrifolia L. (family: Rubiaceae), also known as Noni, has been used by Polynesians for over 2000 years for numerous diseases. The advent of Tahitian Noni Juice generated interest in medicine for its possible beneficial effects on human health and well-being. Almost all parts of the plants are used medicinally in treating a variety of ailments. Palu et al. [122] showed the binding affinities of Noni samples (Tahitian Noni Juice and Noni fruit juice concentrates) for $\mathrm{CB}_{1}$ and $\mathrm{CB}_{2}$ receptors in $\mathrm{CHO}$ $\mathrm{K} 1$ cells expressing hCB receptors using WIN-55,212-2, a nonspecific ligand, and in vivo in mice. Both juices were found to activate $C_{2}$ receptor but inhibit $C_{1}$ receptors. 
Tahitian Noni Juice produced inhibition of CP55,940 for $\mathrm{CB}_{1}$ receptors and enhancement for $\mathrm{CB}_{2}$ receptors. Noni fruit juice concentrate caused stimulation of $\left[{ }^{3} \mathrm{H}\right] \mathrm{WIN}-55,212-2$ binding. At different concentrations the $\mathrm{CB}_{1}$ receptor was inhibited whereas $C_{2}$ receptor showed stimulations at the same concentrations.

The binding activity of Tahitian Noni Juice for $\mathrm{CB}_{1}$ receptors was similar at each concentration, even at fivefold increased concentration. However, at both concentrations a remarkable selectivity for $\mathrm{CB}_{2}$ binding/activation was observed for $\mathrm{CB}_{2}$ receptor [122]. In mice orally administered Tahitian Noni Juice decreased IL- 4 and increased IFN- $\gamma$ suggesting that Noni juice favorably alters the immune system and exhibits immunomodulatory effects by activating the $\mathrm{CB}_{2}$ receptors which are involved in the immune regulation. The dual activity of Noni juice as $\mathrm{CB}_{1}$ receptor inhibitor and $\mathrm{CB}_{2}$ receptor activator has potential benefits in inflammation and immunomodulation.

3.6. Nelumbo nucifera. Nelumbo nucifera Gaertn. (family: Nymphaeaceae), also known as a sacred lotus, is widely distributed across the world and used as food and medicine. The seeds, rhizomes, leaves, flowers, and roots of the plant have been reported to contain megastigmanes including eudesmane sesquiterpenes, nelumnucifosides A and B, alkaloids such as roemerine, nuciferine, nornuciferine, nelumboside, anonaine, 5-methoxy-6-hydroxyaporphine, liensinine, asimilobine, and flavonoids. The cannabinoid activity of both methanol and aqueous extracts of $N$. nucifera was studied in measuring inhibition of CP55,940 elicited $\mathrm{CB}_{2}$ activity in the $\mathrm{G}_{\mathrm{i}} / \mathrm{G}_{\mathrm{o}}$-coupled $\mathrm{CHO}-\mathrm{K} 1$ cell line [123]. The methanolic extract showed antagonism against CP55,940 activity towards $\mathrm{CB}_{2}$ receptor, whereas water extract was found inactive. A potent antagonist activity towards $\mathrm{CP} 55,940$ activated $\mathrm{CB}_{2}$ receptor with an $\mathrm{IC}_{50}$ value of $\sim 62.3 \mathrm{nM}$ was demonstrated by AM630. The study indicated that $N$. nucifera petal extract possesses potential benefits in metabolic disorders mediated by antagonistic effect on $\mathrm{CB}_{2}$ receptors.

3.7. Olea purpurea. Olea europaea (family: Oleaceae), a traditional tree of the Mediterranean basin, is the source of olive oil. The effects of olive oil and its phenolic constituents on gene expression in ECS have been studied in human colon cancer cells (Caco-2). A selective and transient upregulation of CNR1 gene-encoding for $\mathrm{CB}_{1}$ receptor was induced by exposure of Caco-2 cells to the oil. However, the other ECS components such as $\mathrm{CB}_{2}$, GPR55, and TRPV1 receptors and endocannabinoid metabolizing enzymes, NAPE-PLD, DAGL, FAAH, and MAGL, remained unaffected [130].

Further, dietary oil supplementation was found to increase the expression of $\mathrm{CB}_{1}$ in the colon of rats. Following oil supplementation, the methylation of $\mathrm{Cnrl}$ promoter, miR23a, and miR-301a, previously shown to be involved in the pathogenesis of colorectal cancer, was predicted to target $\mathrm{CB}_{1}$ mRNA and appears reduced. In another study, the phenolic compounds of olive oil were developed to allow the preparation of unsaturated derivatives altered food intake in rats owing to their molecular similarity with $\mathrm{CB}_{1}$ endogenous ligands and PPAR- $\alpha$ as potential targets [124]. Taken together, the findings demonstrate modulation of $\mathrm{CB}_{1}$ by olive oil or its phenolic compounds and may provide a new therapeutic avenue for prevention and treatment of cancer and obesity.

3.8. Rubus coreanus Miquel. Rubus coreanus Miquel (family: Rosaceae), also known as Korean black blackberry, is known for its benefits in liver and kidney diseases, spermatorrhoea, prostate, and urinary diseases. It is known to contain tannins such as sanguiin H-4 and sanguiin H-6, flavonoids such as 3,4-dihydroxybenzoic acid, nigaichigoside $\mathrm{F} 1$, nigaichigoside F2, and coreanoside F1, a dimeric triterpene glycosyl ester, and anthocyanins. Its supplementation has shown to enhance antioxidant capacity in men [131]. The cannabinoid receptors mediated activity of Rubus coreanus has been shown in osteoporosis and occurs with N-methyl-N-nitrosourea(MNU-) induced prostatic hyperplasia in aged rats as well as diabetic osteoporosis rats [125] following streptozotocin or ovariectomization [132]. The upregulation of $\mathrm{CB}_{1}$ and $\mathrm{CB}_{2}$ receptors were increased in rats that were ovariectomized and treated with streptozotocin and Rubus coreanus but decreased in those treated with streptozotocin and Rubus coreanus alone. The study revealed that in postmenopausal diabetic and aged rats the antiosteoporotic effect is attributable to the $\mathrm{CB}$ receptor-related upregulation of osteoblastogenesis and inhibition of prostatic hyperplasia. Rubus coreanus rescued bone loss in diabetic and aged osteoporosis by simultaneous alteration of activation in osteoblasts and osteoclasts dependent on upregulation of the ECS. Though, the active component responsible for an effect is yet to be determined.

3.9. Ruta graveolens. Ruta graveolens L. (family: Rutaceae) is a plant of medicinal and culinary importance native to Mediterranean region of southern Europe and northern Africa and Balkans. The plant and phytochemicals isolated have shown to be effective in different types of skin diseases including psoriasis, vitiligo, and cutaneous lymphoma. The dichloromethane and methanol extracts of Ruta graveolens yielded several constituents and were subjected to in silico studies using hitting model for $\mathrm{CB}_{2}$ ligands consisting of the five selective agonists AM1241, GW405833, HU-308, JWH133, and JWH-267 [126]. Of all the molecules subjected to parallel screening, rutamarin showed selective affinity to the $\mathrm{CB}_{2}$ receptor with a $K_{i}$ of $2.64 \pm 0.2 \mu \mathrm{g} / \mathrm{mL}$ or $7.4 \pm 0.6 \mu \mathrm{M}$ in radioligand displacement assay. The findings reveal that rutamarin may provide a novel scaffold for the discovery of $\mathrm{CB}_{2}$ specific ligands.

Miscellaneous Medicinal Plants. Recently, Withania somnifera Dunal, a popular medicinal plant, possesses immunomodulator activity shown to prevent tolerance to the analgesic effect of morphine and suppress rebound hyperalgesia found devoid of affinity for cannabinoid receptors [133]. Hypericum perforatum also known as St. John's wort is a popular plant remedy for depression that did not show cannabinoid property studied using the pharmacological challenge with several agonists and antagonists including SR141716A, $\mathrm{CB}_{1}$ receptor antagonist. However, naloxone significantly reduced the inhibitory effect of Hypericum perforatum on contractions induced by electrical field stimulation mediated 
by opioid receptors [134]. Yuliana et al. [135] evaluated the effects of several dietary spices in the antiobesity related bioactivity screening assays and found that nutmeg, mace, black pepper, and turmeric are capable of modulating the $\mathrm{CB}_{1}$ receptors. El-Alfy et al. [136] also showed that nutmeg extract showed a concentration-dependent inhibition for both FAAH and MAGL. Inhibition of endocannabinoid metabolizing enzymes by nutmeg extracts explains the cannabis-like effect exerted by nutmeg.

\section{Concluding Remarks and Future Prospects}

Compared to synthetic compounds, natural products are known to offer huge structural diversity and the availability of modern techniques for separation, structure elucidation, and screening and combinatorial synthesis will lead to revitalization of plant products as sources of novel drugs. In recent years, several new selective $C_{1}$ and $\mathrm{CB}_{2}$ receptor agents from natural products have been described. Though, several have been identified by these ligands in vitro and in silico studies. However, these molecules are used at micromolar concentrations in the in vitro studies and therefore may show affinity at both receptors. Therefore, additional controls are needed to be performed in order to ensure the selectivity, affinity, potency, and site of action of these molecules.

The in vivo characterization, pharmacokinetic considerations, and the cannabinoid mediated mechanism should be demonstrated for the pharmacological benefit and pharmaceutical development. Moreover, many of these ligands exert prominent CB receptor-independent pharmacological effects, such as activation of the opioid receptors, nicotinic acetylcholine receptors, G-protein-coupled receptor GPR55, peroxisome proliferator-activated receptor gamma, and the transient receptor potential vanilloid channels. The characterization of CB-dependent and CB-independent mechanisms could be further beneficial in developing the multitargeted polypharmacological compound for diseases which involve multiple mechanisms particularly the neurodegenerative and neuropsychiatric diseases where endocannabinoid system dysregulation plays a critical role. Based on current knowledge, the components of ECS may be a system that, under the appropriate conditions, produces synergy with established therapeutic agents in different diseases particularly autoimmune inflammatory diseases.

Currently, there are no clinical data indicating that the use of these ligands as adjuvant or cotreatment could improve the efficacy of the available agents or reduce the dosage thereby reducing the adverse effects and maximizing efficacy. Thus, such clinical comparisons would be very interesting and more research should be directed towards the potential synergism and antagonism of cannabinoid ligands in pharmacotherapeutics. The potential of the ECS in a wide range of disorders has been demonstrated; therefore, it is tempting and reasonable to speculate that the nature derived small molecules modulating cannabinoid receptors will have to demonstrate therapeutic efficacy and elucidate underlying potential mechanism of therapeutic benefits by cannabinoids. Additionally, lack of toxicity along with additional anxiolytic activity which appears with synthetic $\mathrm{CB}_{1}$ receptor antagonists, the phytocannabinoids, can potentially be promising for future armamentarium of the cannabinoid based therapeutics. The data on acute and chronic toxicity and safety is also desired in order to undergo the translation of the observed experimental benefits into humans.

The medicinal plants are part of diet since civilization and therefore based on the evidences of cannabimimetic activity of many more plants could be promoted for inclusion in the diet as these could indirectly exert immunomodulatory, nonpsychoactive, and anti-inflammatory action. This could potentially modulate inflammatory and other pathophysiological processes. The wide availability, easy accessibility, high lipophilicity, and wide therapeutic window make them an excellent candidate for therapeutic intervention. Further, the isolation and characterization of pharmacophores from these plants may provide a model for drug leads using combinatorial chemistry and in silico approaches for future drug discovery. These plants may also offer dietary means of treatment for targeting of endocannabinoid dysregulation or the diseases where endocannabinoid modulation represents an important therapeutic target.

The development of new drugs remains an important task for the pharmaceutical industry. The natural compounds from these herbs could provide a rich source in the search for new candidates targeting GPCRs in particular cannabinoid receptors and ECS. Developing phytocannabinoids possess cannabimimetic activity and being devoid of psychotropic activity will enhance their therapeutic spectrum. To explore this possibility, several herb-based natural compound library and cell-based cannabinoid receptor assays were developed to perform high throughput screening. We believe that the process of assay development for cannabinoid receptors, compound screening using these assays, and hit compounds identification will lead to a successful compound for future therapeutic use.

\section{Conflict of Interests}

The authors declare no conflict of interests.

\section{Acknowledgments}

The author, Shreesh Ojha, is supported by the research grant from National Research Foundation, United Arab Emirates, and College of Medicine and Health Sciences (31M195), United Arab Emirates University, Al Ain, Abu Dhabi, UAE, and Satyesh Sinha was supported by NIH Grant (U54-MD007598) at Charles R. Drew University of Medicine and Science, CA, USA.

\section{References}

[1] R. Mechoulam, S. Ben-Shabat, L. Hanus et al., "Identification of an endogenous 2-monoglyceride, present in canine gut, that binds to cannabinoid receptors," Biochemical Pharmacology, vol. 50, no. 1, pp. 83-90, 1995.

[2] T. Sugiura, S. Kondo, A. Sukagawa et al., "2-arachidonoylglycerol: a possible endogenous cannabinoid receptor ligand in brain," Biochemical and Biophysical Research Communications, vol. 215, no. 1, pp. 89-97, 1995. 
[3] V. Di Marzo and M. Maccarrone, "FAAH and anandamide: is 2AG really the odd one out?" Trends in Pharmacological Sciences, vol. 29, no. 5, pp. 229-233, 2008.

[4] L. Console-Bram, J. Marcu, and M. E. Abood, "Cannabinoid receptors: nomenclature and pharmacological principles," Progress in Neuro-Psychopharmacology and Biological Psychiatry, vol. 38, no. 1, pp. 4-15, 2012.

[5] C. C. Felder, K. E. Joyce, E. M. Briley et al., "Comparison of the pharmacology and signal transduction of the human cannabinoid CB1 and CB2 receptors," Molecular Pharmacology, vol. 48, no. 3, pp. 443-450, 1995.

[6] J. Gertsch, R. G. Pertwee, and V. Di Marzo, "Phytocannabinoids beyond the Cannabis plant-do they exist?" British Journal of Pharmacology, vol. 160, no. 3, pp. 523-529, 2010.

[7] P. Pacher and G. Kunos, "Modulating the endocannabinoid system in human health and disease-successes and failures," FEBS Journal, vol. 280, no. 9, pp. 1918-1943, 2013.

[8] S. Geiger, K. Nickl, E. H. Schneider, R. Seifert, and J. Heilmann, "Establishment of recombinant cannabinoid receptor assays and characterization of several natural and synthetic ligands," Naunyn-Schmiedeberg's Archives of Pharmacology, vol. 382, no. 2, pp. 177-191, 2010.

[9] S. Steffens and P. Pacher, "Targeting cannabinoid receptor $\mathrm{CB}(2)$ in cardiovascular disorders: promises and controversies," British Journal of Pharmacology, vol. 167, no. 2, pp. 313-323, 2012.

[10] J. L. Blankman and B. F. Cravatt, "Chemical probes of endocannabinoid metabolism," Pharmacological Reviews, vol. 65, no. 2, pp. 849-871, 2013.

[11] R. Mechoulam, "Interview with Prof. Raphael mechoulam, codiscoverer of THC.. Interview by Stanley Einstein," The International Journal of the Addictions, vol. 21, no. 4-5, pp. 579$587,1986$.

[12] M. Rinaldi-Carmona, A. Le Duigou, D. Oustric et al., "Modulation of CB1 cannabinoid receptor functions after a longterm exposure to agonist or inverse agonist in the Chinese hamster ovary cell expression system," Journal of Pharmacology and Experimental Therapeutics, vol. 287, no. 3, pp. 1038-1047, 1998.

[13] X.-Q. Xie, L. S. Melvin, and A. Makriyannis, "The conformational properties of the highly selective cannabinoid receptor ligand CP-55,940," Journal of Biological Chemistry, vol. 271, no. 18, pp. 10640-10647, 1996.

[14] L. Hruba, B. C. Ginsburg, and L. R. McMahon, "Apparent inverse relationship between cannabinoid agonist efficacy and tolerance/cross-tolerance produced by $\Delta^{9}$-tetrahydrocannabinol treatment in rhesus monkeys," Journal of Pharmacology and Experimental Therapeutics, vol. 342, no. 3, pp. 843-849, 2012.

[15] S. Ruiu, N. Anzani, A. Orrù et al., "N-Alkyl dien- and trienamides from the roots of Otanthus maritimus with binding affinity for opioid and cannabinoid receptors," Bioorganic and Medicinal Chemistry, vol. 21, no. 22, pp. 7074-7082, 2013.

[16] J. Gertsch, "Anti-inflammatory cannabinoids in diet: towards a better understanding of $\mathrm{CB}_{2}$ receptor action?" Communicative \& Integrative Biology, vol. 1, no. 1, pp. 26-28, 2008.

[17] J. Gertsch, "Immunomodulatory lipids in plants: plant fatty acid amides and the human endocannabinoid system," Planta Medica, vol. 74, no. 6, pp. 638-650, 2008.

[18] J. Gertsch, M. Leonti, S. Raduner et al., "Beta-caryophyllene is a dietary cannabinoid," Proceedings of the National Academy of Sciences of the United States of America, vol. 105, no. 26, pp. 9099-9104, 2008.
[19] K. Woelkart, O. M. H. Salo-Ahen, and R. Bauer, "CB receptor ligands from plants," Current Topics in Medicinal Chemistry, vol. 8, no. 3, pp. 173-186, 2008.

[20] K. Woelkart and R. Bauer, "The role of alkamides as an active principle of Echinacea," Planta Medica, vol. 73, no. 7, pp. 615623, 2007.

[21] K. Woelkart, W. Xu, Y. Pei, A. Makriyannis, R. P. Picone, and R. Bauer, "The endocannabinoid system as a target for alkamides from Echinacea angustifolia roots," Planta Medica, vol. 71, no. 8, pp. 701-705, 2005.

[22] R. G. Pertwee, "Targeting the endocannabinoid system with cannabinoid receptor agonists: pharmacological strategies and therapeutic possibilities," Philosophical Transactions of the Royal Society B: Biological Sciences, vol. 367, no. 1607, pp. 3353-3363, 2012.

[23] S. Zoppi, J. L. Madrigal, J. R. Caso et al., "Regulatory role of the cannabinoid CB2 receptor in stress-induced neuroinflammation in mice," British Journal of Pharmacology, vol. 171, no. 11, pp. 2814-2826, 2014.

[24] S. Rom and Y. Persidsky, "Cannabinoid receptor 2: potential role in immunomodulation and neuroinflammation," Journal of Neuroimmune Pharmacology, vol. 8, no. 3, pp. 608-620, 2013.

[25] A. Chicca, S. Raduner, F. Pellati et al., "Synergistic immunomopharmacological effects of N-alkylamides in Echinacea purpurea herbal extracts," International Immunopharmacology, vol. 9, no. 7-8, pp. 850-858, 2009.

[26] J. Gertsch, R. Schoop, U. Kuenzle, and A. Suter, "Echinacea alkylamides modulate TNF- $\alpha$ gene expression via cannabinoid receptor CB2 and multiple signal transduction pathways," FEBS Letters, vol. 577, no. 3, pp. 563-569, 2004.

[27] S. Raduner, A. Majewska, J.-Z. Chen et al., "Alkylamides from Echinacea are a new class of cannabinomimetics: cannabinoid type 2 receptor-dependent and -independent immunomodulatory effects," The Journal of Biological Chemistry, vol. 281, no. 20, pp. 14192-14206, 2006.

[28] M. Egger, P. Pellett, K. Nickl et al., "Synthesis and cannabinoid receptor activity of ketoalkenes from Echinacea pallida and nonnatural analogues," Chemistry-A European Journal, vol. 14, no. 35, pp. 10978-10984, 2008.

[29] K. Spelman, K. Iiams-Hauser, N. B. Cech, E. W. Taylor, N. Smirnoff, and C. A. Wenner, "Role for PPAR $\gamma$ in IL-2 inhibition in $\mathrm{T}$ cells by Echinacea-derived undeca-2E-ene-8,10-diynoic acid isobutylamide," International Immunopharmacology, vol. 9, no. 11, pp. 1260-1264, 2009.

[30] K. Spelman, M. H. Wetschler, and N. B. Cech, "Comparison of alkylamide yield in ethanolic extracts prepared from fresh versus dry Echinacea purpurea utilizing HPLC-ESI-MS," Journal of Pharmaceutical and Biomedical Analysis, vol. 49, no. 5, pp. 11411149, 2009.

[31] T. Rühl, W. Deuther-Conrad, S. Fischer et al., "Cannabinoid receptor type 2 (CB2)-selective $N$-aryl-oxadiazolyl-propionamides: synthesis, radiolabelling, molecular modelling and biological evaluation," Organic and Medicinal Chemistry Letters, vol. 2, article 32, 2012.

[32] N. Matovic, A. Matthias, J. Gertsch et al., "Stereoselective synthesis, natural occurrence and $\mathrm{CB}_{2}$ receptor binding affinities of alkylamides from herbal medicines such as Echinacea sp.", Organic and Biomolecular Chemistry, vol. 5, no. 1, pp. 169-174, 2007. 
[33] K. A. B. Simão da Silva, A. F. Paszcuk, G. F. Passos et al., "Activation of cannabinoid receptors by the pentacyclic triterpene $\alpha, \beta$-amyrin inhibits inflammatory and neuropathic persistent pain in mice," Pain, vol. 152, no. 8, pp. 1872-1887, 2011.

[34] A. Chicca, J. Marazzi, and J. Gertsch, "The antinociceptive triterpene beta-amyrin inhibits 2-arachidonoylglycerol (2-AG) hydrolysis without directly targeting cannabinoid receptors," British Journal of Pharmacology, vol. 167, no. 8, pp. 1596-1608, 2012.

[35] I. Matos, A. F. Bento, R. Marcon, R. F. Claudino, and J. B. Calixto, "Preventive and therapeutic oral administration of the pentacyclic triterpene $\alpha, \pm$-amyrin ameliorates dextran sulfate sodium-induced colitis in mice: the relevance of cannabinoid system," Molecular Immunology, vol. 54, no. 3-4, pp. 482-492, 2013.

[36] G. Korte, A. Dreiseitel, P. Schreier et al., "An examination of anthocyanins' and anthocyanidins' affinity for cannabinoid receptors," Journal of Medicinal Food, vol. 12, no. 6, pp. 14071410, 2009.

[37] J. Gao, F. León, M. M. Radwan et al., "Benzyl derivatives with in vitro binding affinity for human opioid and cannabinoid receptors from the fungus Eurotium repens," Journal of Natural Products, vol. 74, no. 7, pp. 1636-1639, 2011.

[38] X. Liu, I. Jutooru, P. Lei et al., "Betulinic acid targets YY1 and ErbB2 through cannabinoid receptor-dependent disruption of microRNA-27a:ZBTB10 in breast cancer," Molecular Cancer Therapeutics, vol. 11, no. 7, pp. 1421-1431, 2012.

[39] L. Thors, J. J. Burston, B. J. Alter et al., "Biochanin A, a naturally occurring inhibitor of fatty acid amide hydrolase," British Journal of Pharmacology, vol. 160, no. 3, pp. 549-560, 2010.

[40] A. F. Bento, R. Marcon, R. C. Dutra et al., " $\beta$-caryophyllene inhibits dextran sulfate sodium-induced colitis in mice through CB2 receptor activation and PPAR $\gamma$ pathway," American Journal of Pathology, vol. 178, no. 3, pp. 1153-1166, 2011.

[41] S. Al Mansouri, S. Ojha, E. Al Maamari, M. Al Ameri, S. M. Nurulain, and A. Bahi, "The cannabinoid receptor 2 agonist, beta-caryophyllene, reduced voluntary alcohol intake and attenuated ethanol-induced place preference and sensitivity in mice," Pharmacology Biochemistry and Behavior, vol. 124, pp. 260-268, 2014.

[42] K. Guo, X. Mou, J. Huang, N. Xiong, and H. Li, “Transcaryophyllene suppresses hypoxia-induced neuroinflammatory responses by inhibiting NF- $\kappa$ B activation in microglia," Journal of Molecular Neuroscience, vol. 54, no. 1, pp. 41-48, 2014.

[43] I.-Y. Choi, C. Ju, A. M. A. Anthony Jalin, D. I. Lee, P. L. Prather, and W.-K. Kim, "Activation of cannabinoid CB2 receptormediated AMPK/CREB pathway reduces cerebral ischemic injury," The American Journal of Pathology, vol. 182, no. 3, pp. 928-939, 2013.

[44] W. Suijun, Y. Zhen, G. Ying, and W. Yanfang, "A role for trans-caryophyllene in the moderation of insulin secretion," Biochemical and Biophysical Research Communications, vol. 444, no. 4, pp. 451-454, 2014.

[45] L. C. Assis, M. R. Straliotto, D. Engel, M. A. Hort, R. C. Dutra, and A. F. de Bem, "Beta-Caryophyllene protects the C6 glioma cells against glutamate-induced excitotoxicity through the Nrf2 pathway," Neuroscience, vol. 279, pp. 220-231, 2014.

[46] X. Zheng, T. Sun, and X. Wang, "Activation of type 2 cannabinoid receptors (CB2R) promotes fatty acid oxidation through the SIRT1/PGC-1 $\alpha$ pathway," Biochemical and Biophysical Research Communications, vol. 436, no. 3, pp. 377-381, 2013.
[47] B. Horváth, P. Mukhopadhyay, M. Kechrid et al., " $\beta$-caryophyllene ameliorates cisplatin-induced nephrotoxicity in a cannabinoid 2 receptor-dependent manner," Free Radical Biology and Medicine, vol. 52, no. 8, pp. 1325-1333, 2012.

[48] M. F. Mahmoud, S. E. Swefy, R. A. Hasan, and A. Ibrahim, "Role of cannabinoid receptors in hepatic fibrosis and apoptosis associated with bile duct ligation in rats," European Journal of Pharmacology, vol. 742, pp. 118-124, 2014.

[49] A. Bahi, S. Al Mansouri, E. Al Memari, M. Al Ameri, S. M. Nurulain, and S. Ojha, “ $\beta$-caryophyllene, a CB2 receptor agonist produces multiple behavioral changes relevant to anxiety and depression in mice," Physiology and Behavior, vol. 135, pp. 119-124, 2014.

[50] A.-L. Klauke, I. Racz, B. Pradier et al., “The cannabinoid $\mathrm{CB}_{2}$ receptor-selective phytocannabinoid beta-caryophyllene exerts analgesic effects in mouse models of inflammatory and neuropathic pain," European Neuropsychopharmacology, vol. 24, no. 4, pp. 608-620, 2014.

[51] Y. Cheng, Z. Dong, and S. Liu, “ $\beta$-Caryophyllene ameliorates the Alzheimer-like phenotype in APP/PS1 Mice through CB2 receptor activation and the PPAR $\gamma$ pathway," Pharmacology, vol. 94, pp. 1-12, 2014.

[52] S. Katsuyama, H. Mizoguchi, H. Kuwahata et al., "Involvement of peripheral cannabinoid and opioid receptors in bcaryophyllene-induced antinociception," European Journal of Pain, vol. 17, no. 5, pp. 664-675, 2013.

[53] A. Chicca, D. Caprioglio, A. Minassi et al., "Functionalization of $\beta$-caryophyllene generates novel polypharmacology in the endocannabinoid system," ACS Chemical Biology, vol. 9, no. 7, pp. 1499-1507, 2014.

[54] G. Korte, A. Dreiseitel, P. Schreier et al., "Tea catechins' affinity for human cannabinoid receptors," Phytomedicine, vol. 17, no. 1, pp. 19-22, 2010.

[55] L. Yang, Y. Li, J. Ren et al., "Celastrol attenuates inflammatory and neuropathic pain mediated by cannabinoid receptor type 2," International Journal of Molecular Sciences, vol. 15, no. 8, pp. 13637-13648, 2014.

[56] A. S. Dhopeshwarkar and R. A. Nicholson, "Benzophenanthridine alkaloid, piperonyl butoxide and (S)-methoprene action at the cannabinoid-1 receptor $\left(\mathrm{CB}_{1}\right.$-receptor) pathway of mouse brain: interference with $\left[{ }^{3} \mathrm{H}\right] \mathrm{CP} 55940$ and $\left[{ }^{3} \mathrm{H}\right] \mathrm{SR} 141716 \mathrm{~A}$ binding and modification of WIN55212-2-dependent inhibition of synaptosomal l-glutamate release," European Journal of Pharmacology, vol. 723, no. 1, pp. 431-441, 2014.

[57] G. Lim, B. Sung, R.-R. Ji, and J. Mao, "Upregulation of spinal cannabinoid-1-receptors following nerve injury enhances the effects of win 55,212-2 on neuropathic pain behaviors in rats," Pain, vol. 105, no. 1-2, pp. 275-283, 2003.

[58] V. Rubovitch, M. Gafni, and Y. Sarne, "The involvement of VEGF receptors and MAPK in the cannabinoid potentiation of $\mathrm{Ca}^{2+}$ flux into N18TG2 neuroblastoma cells," Molecular Brain Research, vol. 120, no. 2, pp. 138-144, 2004.

[59] A. S. Dhopeshwarkar, S. Jain, C. Liao, S. K. Ghose, K. M. Bisset, and R. A. Nicholson, "The actions of benzophenanthridine alkaloids, piperonyl butoxide and (S)-methoprene at the Gprotein coupled cannabinoid $\mathrm{CB}_{1}$ receptor in vitro," European Journal of Pharmacology, vol. 654, no. 1, pp. 26-32, 2011.

[60] M. Steffens, J. Zentner, J. Honegger, and T. J. Feuerstein, "Binding affinity and agonist activity of putative endogenous cannabinoids at the human neocortical CB1 receptor," Biochemical Pharmacology, vol. 69, no. 1, pp. 169-178, 2005. 
[61] A. Thomas, L. A. Stevenson, K. N. Wease et al., "Evidence that the plant cannabinoid $\Delta^{9}$ - tetrahydrocannabivarin is a cannabinoid $\mathrm{CB}_{1}$ and $\mathrm{CB}_{2}$ receptor antagonist," British Journal of Pharmacology, vol. 146, no. 7, pp. 917-926, 2005.

[62] M. R. Romano and M. D. Lograno, "Signaling cross-talk between cannabinoid and muscarinic systems actives Rhokinase and increases the contractile responses of the bovine ciliary muscle," European Journal of Pharmacology, vol. 702, no. 1-3, pp. 174-179, 2013.

[63] K. A. Seely, M. S. Levi, and P. L. Prather, "The dietary polyphenols trans-resveratrol and curcumin selectively bind human CB1 cannabinoid receptors with nanomolar affinities and function as antagonists/inverse agonists," Journal of Pharmacology and Experimental Therapeutics, vol. 330, no. 1, pp. 31-39, 2009.

[64] P. Hassanzadeh and A. Hassanzadeh, "The $\mathrm{CB}_{1}$ receptormediated endocannabinoid signaling and NGF: the novel targets of curcumin," Neurochemical Research, vol. 37, no. 5, pp. 1112-1120, 2012.

[65] J. M. Witkin, S. Leucke, L. K. Thompson et al., "Further evaluation of the neuropharmacological determinants of the antidepressant-like effects of curcumin," CNS \& Neurological Disorders-Drug Targets, vol. 12, no. 4, pp. 498-505, 2013.

[66] Z. Zhang, Y. Guo, S. Zhang et al., "Curcumin modulates cannabinoid receptors in liver fibrosis in vivo and inhibits extracellular matrix expression in hepatic stellate cells by suppressing cannabinoid receptor type-1 in vitro," European Journal of Pharmacology, vol. 721, no. 1-3, pp. 133-140, 2013.

[67] P. J. Lee, S. J. Woo, J. G. Jee, S. H. Sung, and H. P. Kim, “Bisdemethoxycurcumin induces apoptosis in activated hepatic stellate cells via cannabinoid receptor 2," Molecules, vol. 20, no. 1, pp. 1277-1292, 2015.

[68] G. Chianese, E. Fattorusso, O. Taglialatela-Scafati et al., "Desulfohaplosamate, a new phosphate-containing steroid from Dasychalina sp., is a selective cannabinoid $\mathrm{CB}_{2}$ receptor ligand," Steroids, vol. 76, no. 10-11, pp. 998-1002, 2011.

[69] A. Pereira, T. A. Pfeifer, T. A. Grigliatti, and R. J. Andersen, "Functional cell-based screening and saturation transfer double-difference NMR have identified haplosamate A as a cannabinoid receptor agonist," ACS Chemical Biology, vol. 4, no. 2, pp. 139-144, 2009.

[70] A. R. King, E. Y. Dotsey, A. Lodola et al., "Discovery of potent and reversible monoacylglycerol lipase inhibitors," Chemistry \& Biology, vol. 16, no. 10, pp. 1045-1052, 2009.

[71] R. C. Dutra, K. A. B. Simão da Silva, A. F. Bento et al., "Euphol, a tetracyclic triterpene produces antinociceptive effects in inflammatory and neuropathic pain: the involvement of cannabinoid system," Neuropharmacology, vol. 63, no. 4, pp. 593-605, 2012.

[72] M. Leonti, L. Casu, S. Raduner et al., "Falcarinol is a covalent cannabinoid $\mathrm{CB}_{1}$ receptor antagonist and induces pro-allergic effects in skin," Biochemical Pharmacology, vol. 79, no. 12, pp. 1815-1826, 2010.

[73] M. Park, J.-H. Lee, J. K. Choi et al., "18 $\beta$-glycyrrhetinic acid attenuates anandamide-induced adiposity and high-fat diet induced obesity," Molecular Nutrition and Food Research, vol. 58, no. 7, pp. 1436-1446, 2014.

[74] S. Nicolussi, A. Chicca, M. Rau et al., "Correlating FAAH and anandamide cellular uptake inhibition using $N$-alkylcarbamate inhibitors: from ultrapotent to hyperpotent," Biochemical Pharmacology, vol. 92, no. 4, pp. 669-689, 2014.
[75] S. Nicolussi, J. M. Viveros-Paredes, M. S. Gachet et al., "Guineensine is a novel inhibitor of endocannabinoid uptake showing cannabimimetic behavioral effects in BALB/c mice," Pharmacological Research, vol. 80, pp. 52-65, 2014.

[76] R. Capasso, A. A. Izzo, F. Borrelli et al., "Effect of piperine, the active ingredient of black pepper, on intestinal secretion in mice," Life Sciences, vol. 71, no. 19, pp. 2311-2317, 2002.

[77] A. A. Izzo, R. Capasso, L. Pinto, G. D. Carlo, N. Mascolo, and F. Capasso, "Effect of vanilloid drugs on gastrointestinal transit in mice," British Journal of Pharmacology, vol. 132, no. 7, pp. 14111416, 2001.

[78] M. van der Stelt, J. A. van Kuik, M. Bari et al., "Oxygenated metabolites of anandamide and 2-arachidonoylglycerol: conformational analysis and interaction with cannabinoid receptors, membrane transporter, and fatty acid amide hydrolase," Journal of Medicinal Chemistry, vol. 45, no. 17, pp. 3709-3720, 2002.

[79] V. Rempel, A. Fuchs, S. Hinz et al., "Magnolia extract, magnolol, and metabolites: activation of cannabinoid CB2 receptors and blockade of the related GPR55," ACS Medicinal Chemistry Letters, vol. 4, no. 1, pp. 41-45, 2013.

[80] A. Fuchs, V. Rempel, and C. E. Müller, "The natural product magnolol as a lead structure for the development of potent cannabinoid receptor agonists," PloS one, vol. 8, no. 10, Article ID e77739, 2013.

[81] H. Zhang, X. Xu, L. Chen et al., "Molecular determinants of magnolol targeting both RXRalpha and PPARgamma," PLoS ONE, vol. 6, no. 11, Article ID e28253, 2011.

[82] R. Montaser, V. J. Paul, and H. Luesch, "Marine cyanobacterial fatty acid amides acting on cannabinoid receptors," ChemBioChem, vol. 13, no. 18, pp. 2676-2681, 2012.

[83] K.-Y. Su, C. Y. Yu, Y.-W. Chen et al., "Rutin, a flavonoid and principal component of Saussurea involucrata, attenuates physical fatigue in a forced swimming mouse model," International Journal of Medical Sciences, vol. 11, no. 5, pp. 528-537, 2014.

[84] M. Gutiérrez, A. R. Pereira, H. M. Debonsi, A. Ligresti, V. Di Marzo, and W. H. Gerwick, "Cannabinomimetic lipid from a marine cyanobacterium," Journal of Natural Products, vol. 74, no. 10, pp. 2313-2317, 2011.

[85] W. Schuehly, J. M. V. Paredes, J. Kleyer et al., "Mechanisms of osteoclastogenesis inhibition by a novel class of biphenyltype cannabinoid $\mathrm{CB}_{2}$ receptor inverse agonists," Chemistry and Biology, vol. 18, no. 8, pp. 1053-1064, 2011.

[86] J. H. Oh, L. L. Kang, J. O. Ban et al., "Anti-inflammatory effect of 4-O-methylhonokiol, a novel compound isolated from Magnolia officinalis through inhibition of NF- $\kappa \mathrm{B}$," ChemicoBiological Interactions, vol. 180, no. 3, pp. 506-514, 2009.

[87] J. Gertsch and S. Anavi-Goffer, "Methylhonokiol attenuates neuroinflammation: a role for cannabinoid receptors?" Journal of Neuroinflammation, vol. 9, article 135, 2012.

[88] O. Ofek, M. Karsak, N. Leclerc et al., "Peripheral cannabinoid receptor, $\mathrm{CB}_{2}$, regulates bone mass," Proceedings of the National Academy of Sciences of the United States of America, vol. 103, no. 3, pp. 696-701, 2006.

[89] A. H. Tarawneh, F. León, M. A. Ibrahim, S. Pettaway, C. R. McCurdy, and S. J. Cutler, "Flavanones from Miconia prasina," Phytochemistry Letters, vol. 7, pp. 130-132, 2014.

[90] J. L. Bolton, S. B. Turnipseed, and J. A. Thompson, "Influence of quinone methide reactivity on the alkylation of thiol and amino groups in proteins: studies utilizing amino acid and peptide models," Chemico-Biological Interactions, vol. 107, no. 3, pp. 185200, 1997. 
[91] L. K. Brents, F. Medina-Bolivar, K. A. Seely et al., "Natural prenylated resveratrol analogs arachidin-1 and -3 demonstrate improved glucuronidation profiles and have affinity for cannabinoid receptors," Xenobiotica, vol. 42, no. 2, pp. 139-156, 2012.

[92] J. Gao, M. M. Radwan, F. Leon et al., "Correction to Neocosmospora sp.-derived resorcylic acid lactones with in vitro binding affinity for human opioid and cannabinoid receptors," Journal of Natural Products, vol. 76, no. 11, article 2174, 2013.

[93] J. Gao, M. M. Radwan, F. León et al., "Neocosmospora sp.derived resorcylic acid lactones with in vitro binding affinity for human opioid and cannabinoid receptors," Journal of Natural Products, vol. 76, no. 5, pp. 824-828, 2013.

[94] B. L. Roth, K. Baner, R. Westkaemper et al., "Salvinorin A: a potent naturally occurring nonnitrogenous $\kappa$ opioid selective agonist," Proceedings of the National Academy of Sciences of the United States of America, vol. 99, no. 18, pp. 11934-11939, 2002.

[95] D. Braida, V. Capurro, A. Zani et al., "Potential anxiolyticand antidepressant-like effects of salvinorin A, the main active ingredient of Salvia divinorum, in rodents," British Journal of Pharmacology, vol. 157, no. 5, pp. 844-853, 2009.

[96] D. M. Walentiny, R. E. Vann, J. A. Warner et al., "Kappa opioid mediation of cannabinoid effects of the potent hallucinogen, salvinorin A, in rodents," Psychopharmacology, vol. 209, no. 2, pp. 275-284, 2010.

[97] D. Braida, V. Limonta, V. Capurro et al., "Involvement of kappaopioid and endocannabinoid system on Salvinorin A-induced reward," Biological Psychiatry, vol. 63, no. 3, pp. 286-292, 2008.

[98] R. Capasso, F. Borrelli, M. G. Cascio et al., "Inhibitory effect of salvinorin A, from Salvia divinorum, on ileitis-induced hypermotility: cross-talk between kappa-opioid and cannabinoid $\mathrm{CB}_{1}$ receptors," British Journal of Pharmacology, vol. 155, no. 5, pp. 681-689, 2008.

[99] D. Braida, V. Limonta, S. Pegorini et al., "Hallucinatory and rewarding effect of salvinorin $\mathrm{A}$ in zebrafish: $\kappa$-opioid and $\mathrm{CB}_{1}$ cannabinoid receptor involvement," Psychopharmacology, vol. 190, no. 4, pp. 441-448, 2007.

[100] G. Aviello, F. Borrelli, F. Guida et al., "Ultrapotent effects of salvinorin A, a hallucinogenic compound from Salvia divinorum, on LPS-stimulated murine macrophages and its antiinflammatory action in vivo," Journal of Molecular Medicine, vol. 89, no. 9, pp. 891-902, 2011.

[101] F. Guida, L. Luongo, G. Aviello et al., "Salvinorin A reduces mechanical allodynia and spinal neuronal hyperexcitability induced by peripheral formalin injection," Molecular Pain, vol. 8, article 60, 2012.

[102] J. Fichna, M. Dicay, K. Lewellyn et al., "Salvinorin A has antiinflammatory and antinociceptive effects in experimental models of colitis in mice mediated by KOR and CB1 receptors," Inflammatory Bowel Diseases, vol. 18, no. 6, pp. 1137-1145, 2012.

[103] J. Fichna, R. Schicho, C. N. Andrews et al., "Salvinorin A inhibits colonic transit and neurogenic ion transport in mice by activating kappa-opioid and cannabinoid receptors," Neurogastroenterology \& Motility, vol. 21, no. 12, pp. 1326-e128, 2009.

[104] J. Fichna, R. Schicho, A. Janecka, J. K. Zjawiony, and M. Storr, "Selective natural $\kappa$ opioid and cannabinoid receptor agonists with a potential role in the treatment of gastrointestinal dysfunction," Drug News and Perspectives, vol. 22, no. 7, pp. 383392, 2009.
[105] J. Fichna, M. Dicay, S. A. Hirota et al., "Differential effects of salvinorin A on endotoxin-induced hypermotility and neurogenic ion transport in mouse ileum," Neurogastroenterology and Motility, vol. 23, no. 6, p. 583-e212, 2011.

[106] K. S. S. Dossou, K. P. Devkota, C. Morton et al., "Identification of CB1/CB2 ligands from Zanthoxylum bungeanum," Journal of Natural Products, vol. 76, no. 11, pp. 2060-2064, 2013.

[107] S. Nakane, T. Tanaka, K. Satouchi, Y. Kobayashi, K. Waku, and T. Sugiura, "Occurrence of a novel cannabimimetic molecule 2sciadonoylglycerol (2-eicosa- $5^{\prime}, 11^{\prime}, 14^{\prime}$-trienoylglycerol) in the umbrella pine Sciadopitys verticillata seeds," Biological and Pharmaceutical Bulletin, vol. 23, no. 6, pp. 758-761, 2000.

[108] B. Han, K. L. McPhail, A. Ligresti, V. Di Marzo, and W. H. Gerwick, "Semiplenamides A-G, fatty acid amides from a Papua New Guinea collection of the marine cyanobacterium Lyngbya semiplena," Journal of Natural Products, vol. 66, no. 10, pp. 13641368, 2003.

[109] J. H. Greenberg, A. Mellors, and J. C. McGowan, "Molar volume relationships and the specific inhibition of a synaptosomal enzyme by psychoactive cannabinoids," Journal of Medicinal Chemistry, vol. 21, no. 12, pp. 1208-1212, 1978.

[110] J. P. Meschler and A. C. Howlett, "Thujone exhibits low affinity for cannabinoid receptors but fails to evoke cannabimimetic responses," Pharmacology Biochemistry and Behavior, vol. 62, no. 3, pp. 473-480, 1999.

[111] M. Kitajima, M. Iwai, R. Kikura-Hanajiri et al., "Discovery of indole alkaloids with cannabinoid CB1 receptor antagonistic activity," Bioorganic \& Medicinal Chemistry Letters, vol. 21, no. 7, pp. 1962-1964, 2011.

[112] A. Ligresti, R. Villano, M. Allarà, I. Ujváry, and V. Di Marzo, "Kavalactones and the endocannabinoid system: the plantderived yangonin is a novel $\mathrm{CB}_{1}$ receptor ligand," Pharmacological Research, vol. 66, no. 2, pp. 163-169, 2012.

[113] B. Botta, E. Gacs-Baitz, V. Vinciguerra, and G. Delle Monache, "Three isoflavanones with cannabinoid-like moieties from Desmodium canum," Phytochemistry, vol. 64, no. 2, pp. 599-602, 2003.

[114] M. Toyota, T. Shimamura, H. Ishii, M. Renner, J. Braggins, and Y. Asakawa, "New bibenzyl cannabinoid from the New Zealand liverwort Radula marginata," Chemical and Pharmaceutical Bulletin, vol. 50, no. 10, pp. 1390-1392, 2002.

[115] K. Soderstrom, T. F. Murray, H.-D. Yoo et al., "Discovery of novel cannabinoid receptor ligands from diverse marine organisms," in Recent Advances in Prostaglandin, Thromboxane, and Leukotriene Research, vol. 433 of Advances in Experimental Medicine and Biology, pp. 73-77, Springer, New York, NY, USA, 1997.

[116] E. di Tomaso, M. Beltramo, and D. Piomelli, "Brain cannabinoids in chocolate," Nature, vol. 382, no. 6593, pp. 677-678, 1996.

[117] I. Gómez-Betancur, N. Cortés, D. Benjumea, E. Osorio, F. León, and S. J. Cutler, "Antinociceptive activity of extracts and secondary metabolites from wild growing and micropropagated plants of Renealmia alpinia," Journal of Ethnopharmacology, vol. 165, pp. 191-197, 2015.

[118] F. León, J. Gao, O. R. Dale et al., "Secondary metabolites from Eupenicillium parvum and their in vitro binding affinity for human opioid and cannabinoid receptors," Planta Medica, vol. 79, no. 18, pp. 1756-1761, 2013.

[119] J.-Y. Huang, M. Fang, Y.-J. Li, Y.-Q. Ma, and X.-H. Cai, "Analgesic effect of Corydalis yanhusuo in a rat model of trigeminal neuropathic pain," Nan Fang Yi Ke Da Xue Xue Bao, vol. 30, no. 9, pp. 2161-2164, 2010. 
[120] M. Styrczewska, A. Kulma, K. Ratajczak, R. Amarowicz, and J. Szopa, "Cannabinoid-like anti-inflammatory compounds from flax fiber," Cellular and Molecular Biology Letters, vol. 17, no. 3, pp. 479-499, 2012.

[121] M.-W. Liu, M.-X. Su, Y.-H. Wang et al., "Effect of melilotus extract on lung injury by upregulating the expression of cannabinoid CB2 receptors in septic rats," BMC Complementary and Alternative Medicine, vol. 14, article 94, 2014.

[122] A. K. Palu, A. H. Kim, B. J. West, S. Deng, J. Jensen, and L. White, "The effects of Morinda citrifolia L. (noni) on the immune system: its molecular mechanisms of action," Journal of Ethnopharmacology, vol. 115, no. 3, pp. 502-506, 2008.

[123] C. C. Velusami, A. Agarwal, and V. Mookambeswaran, "Effect of nelumbo nucifera petal extracts on lipase, adipogenesis, adipolysis, and central receptors of obesity," Evidence-Based Complementary and Alternative Medicine, vol. 2013, Article ID 145925, 7 pages, 2013.

[124] B. A. Cotrim, J. Joglar, M. J. L. Rojas et al., "Unsaturated fatty alcohol derivatives of olive oil phenolic compounds with potential low-density lipoprotein (LDL) antioxidant and antiobesity properties," Journal of Agricultural and Food Chemistry, vol. 60, no. 4, pp. 1067-1074, 2012.

[125] H.-K. Lim, H.-R. Lee, and S. H. Do, "Stimulation of cannabinoid receptors by using Rubus coreanus extracts to control osteoporosis in aged male rats," The Aging Male, vol. 18, no. 2, pp. 124-132, 2015.

[126] J. M. Rollinger, D. Schuster, B. Danzl et al., "In silico target fishing for rationalized ligand discovery exemplified on constituents of Ruta graveolens," Planta Medica, vol. 75, no. 3, pp. 195-204, 2009.

[127] H. Henkes, M. Franz, O. Kendall et al., "Evaluation of the anxiolytic properties of Tetrahydropalmatine, a Corydalis yanhusuo compound, in the male Sprague-Dawley rat," AANA Journal, vol. 79, no. 4, pp. S75-S80, 2011.

[128] J. Hohmann, D. Rédei, P. Forgo et al., "Alkamides and a neolignan from Echinacea purpurea roots and the interaction of alkamides with G-protein-coupled cannabinoid receptors," Phytochemistry, vol. 72, no. 14-15, pp. 1848-1853, 2011.

[129] S. Raduner, W. Bisson, R. Abagyan, K.-H. Altmann, and J. Gertsch, "Self-assembling cannabinomimetics: supramolecular structures of N-alkyl amides," Journal of Natural Products, vol. 70, no. 6, pp. 1010-1015, 2007.

[130] A. Di Francesco, A. Falconi, C. Di Germanio et al., "Extravirgin olive oil up-regulates $\mathrm{CB}_{1}$ tumor suppressor gene in human colon cancer cells and in rat colon via epigenetic mechanisms," Journal of Nutritional Biochemistry, vol. 26, no. 3, pp. 250-258, 2015.

[131] J. E. Lee, E. Park, J. E. Lee et al., "Effects of a Rubus coreanus Miquel supplement on plasma antioxidant capacity in healthy Korean men," Nutrition Research and Practice, vol. 5, no. 5, pp. 429-434, 2011.

[132] C. Choi, H. Lee, H. Lim, S. Park, J. Lee, and S. Do, "Effect of Rubus coreanus extracts on diabetic osteoporosis by simultaneous regulation of osteoblasts and osteoclasts," Menopause, vol. 19, no. 9, pp. 1043-1051, 2012.

[133] A. Orrù, G. Marchese, G. Casu et al., "Withania somnifera root extract prolongs analgesia and suppresses hyperalgesia in mice treated with morphine," Phytomedicine, vol. 21, no. 5, pp. 745$752,2014$.
[134] R. Capasso, F. Borrelli, F. Capasso, N. Mascolo, and A. A. Izzo, "Inhibitory effect of the antidepressant St. John's Wort (hypericum perforatum) on rat bladder contractility in vitro," Urology, vol. 64, no. 1, pp. 168-172, 2004.

[135] N. D. Yuliana, M. Iqbal, M. Jahangir et al., "Screening of selected Asian spices for anti obesity-related bioactivities," Food Chemistry, vol. 126, no. 4, pp. 1724-1729, 2011.

[136] A. T. El-Alfy, L. Wilson, M. A. ElSohly, and E. A. Abourashed, "Towards a better understanding of the psychopharmacology of nutmeg: activities in the mouse tetrad assay," Journal of Ethnopharmacology, vol. 126, no. 2, pp. 280-286, 2009. 


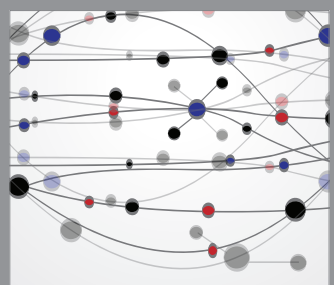

The Scientific World Journal
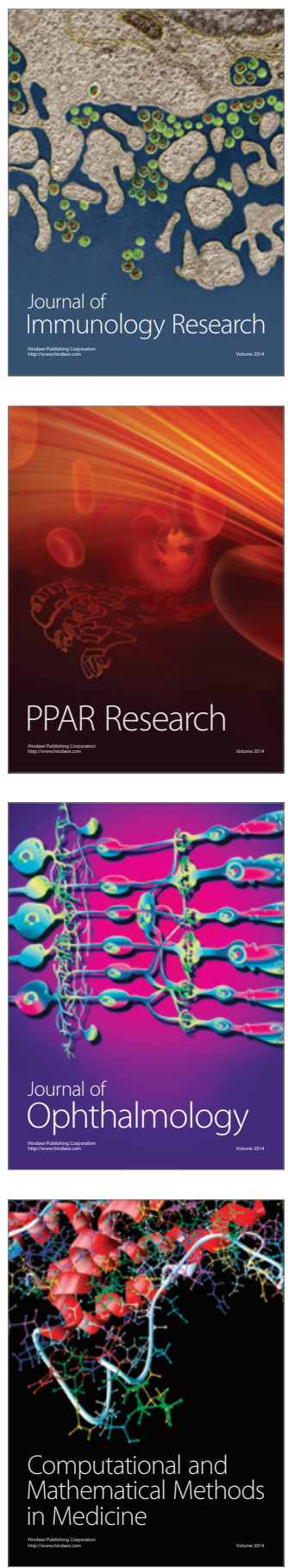

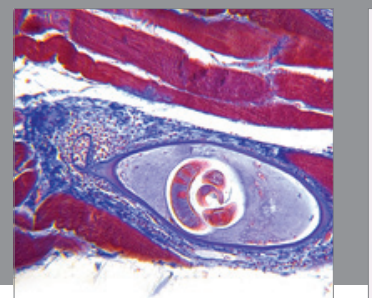

Gastroenterology

Research and Practice
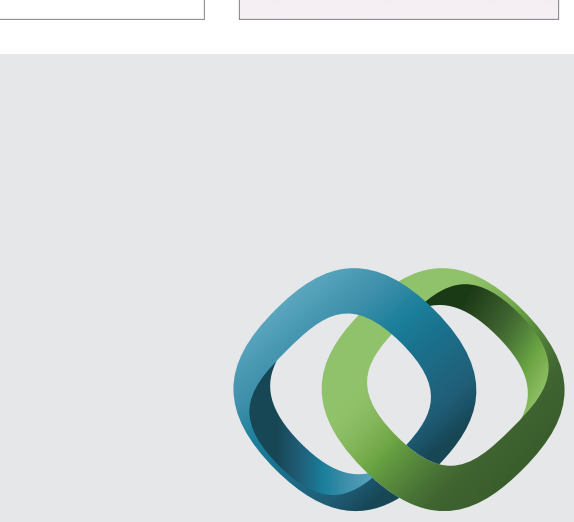

\section{Hindawi}

Submit your manuscripts at

http://www.hindawi.com
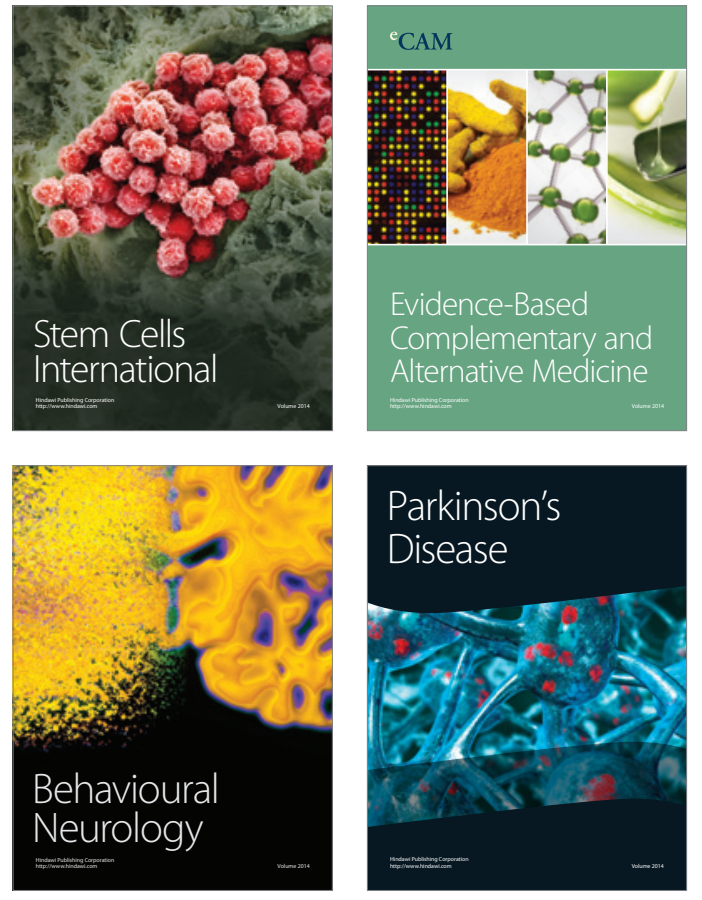
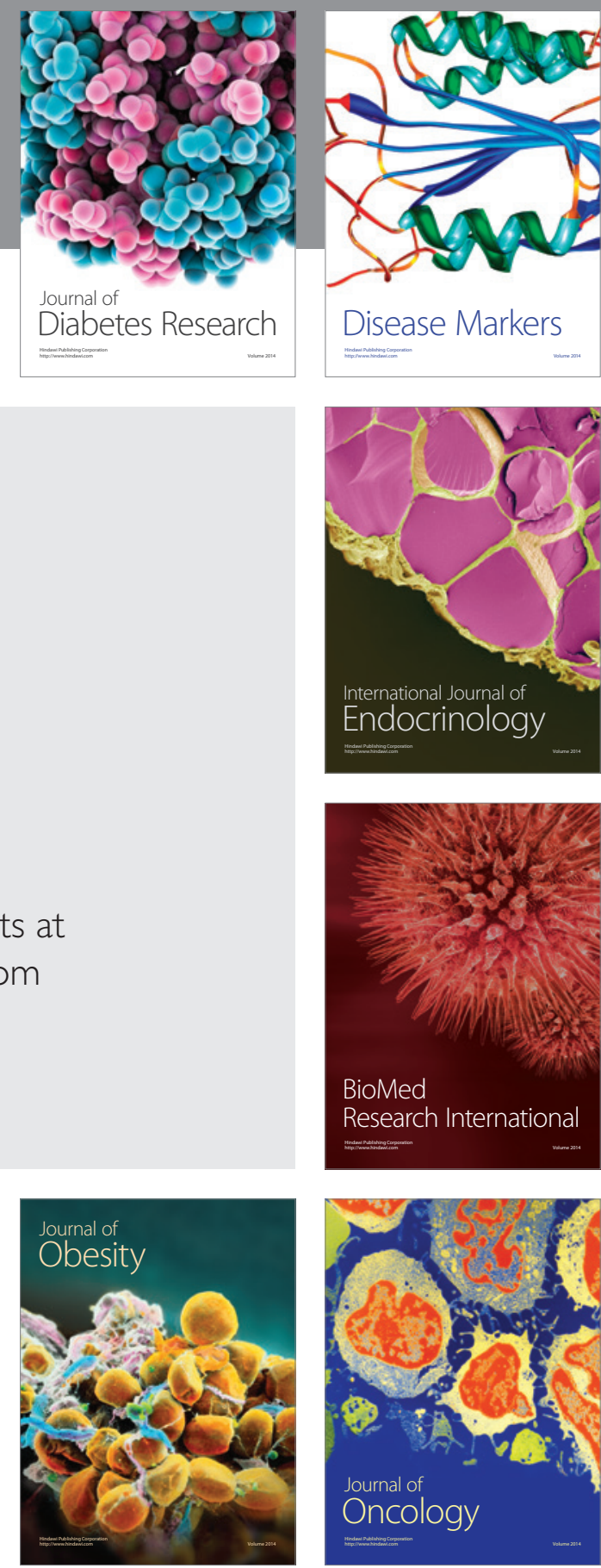

Disease Markers
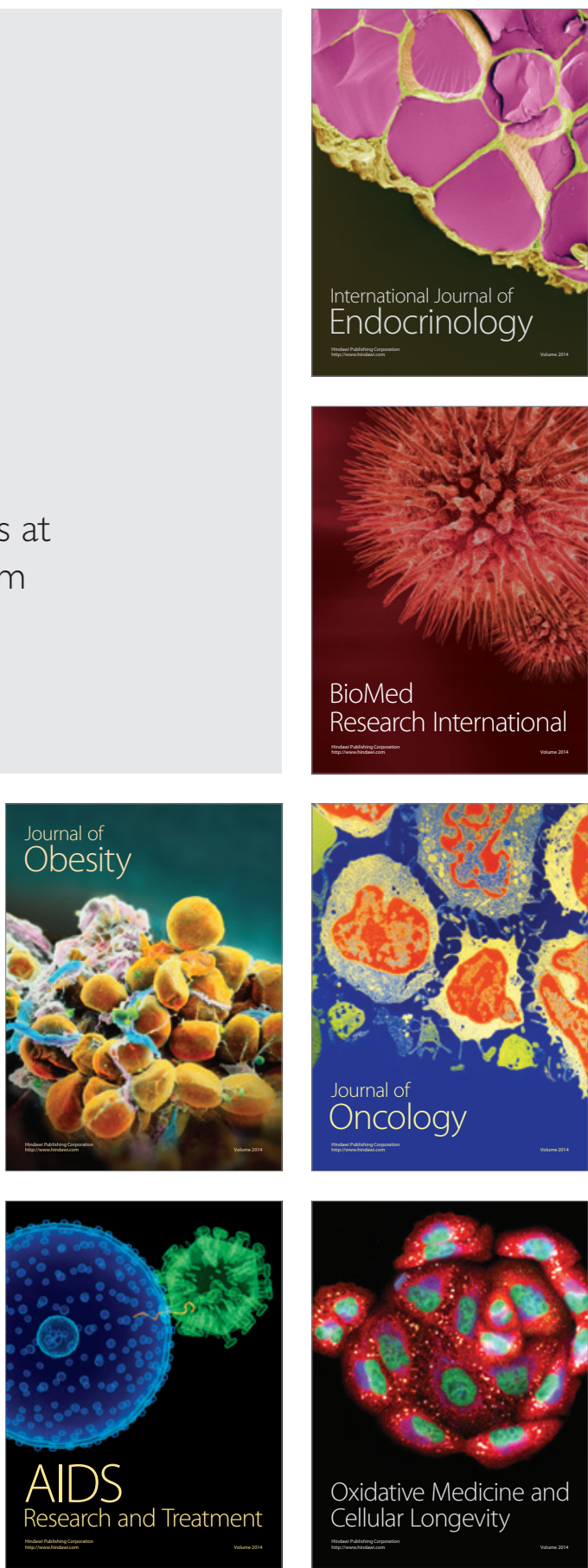